\title{
Glycosylated Natural Products From Marine Microbes
}

\author{
Kunlong $\mathrm{Li}^{1,2}$, Jian Cai ${ }^{1,2}$, Ziqi Su ${ }^{3}$, Bin Yang ${ }^{1}$, Yonghong Liu ${ }^{1}$, Xuefeng Zhou ${ }^{1,2 *}$, \\ Jingxia Huang ${ }^{4 *}$ and Huaming Tao $^{3 *}$
}

${ }^{1}$ CAS Key Laboratory of Tropical Marine Bio-Resources and Ecology/Guangdong Key Laboratory of Marine Materia Medica, South China Sea Institute of Oceanology, Chinese Academy of Sciences, Guangzhou, China, ${ }^{2}$ College of Earth and Planetary Sciences, University of Chinese Academy of Sciences, Beijing, China, ${ }^{3}$ School of Traditional Chinese Medicine, Southern Medical University, Guangzhou, China, ${ }^{4}$ State Key Laboratory of Ophthalmology, Zhongshan Ophthalmic Center, Sun Yat-sen University, Guangzhou, China

\section{OPEN ACCESS}

Edited by:

Huiming Ge,

Nanjing University, China

Reviewed by:

Michele Mari,

Department of Biomolecular Sciences, School of Pharmacy, University of

Urbino Carlo Bo, Italy

Cheng Fang,

Biogen Idec, United States

*Correspondence: Xuefeng Zhou

xfzhou@scsio.ac.cn Jingxia Huang

13694217880@163.com Huaming Tao

taohm@smu.edu.cn

Specialty section:

This article was submitted to

Medicinal and Pharmaceutical

Chemistry,

a section of the journal

Frontiers in Chemistry

Received: 15 October 2019 Accepted: 05 December 2019

Published: 10 January 2020

Citation:

Li K, Cai J, Su Z, Yang B, Liu Y,

Zhou X, Huang J and Tao H (2020)

Glycosylated Natural Products From

Marine Microbes. Front. Chem. 7:879.

doi: 10.3389/fchem.2019.00879
A growing body of evidence indicates that glycosylated natural products have become vital platforms for the development of many existing first-line drugs. This review covers 205 new glycosides over the last 22 years (1997-2018), from marine microbes, including bacteria, cyanobacteria, and fungi. Herein, we discuss the structures and biological activities of these compounds, as well as the details of their source organisms.

Keywords: marine microbes, bacteria, cyanobacteria, fungi, glycosides

\section{INTRODUCTION}

Sugars are ubiquitous in nature and have a multitude of functions, ranging from serving as a simple source of energy to contributing to molecular-recognition scaffolds that are critical to the interactions/communication among a wide array of biomolecules, cells, tissues, and organisms (Gantt et al., 2011). Not only do sugars work alone in the processes of life, but also they play an important role by combing with secondary metabolites. For instance, glycolipids are carbohydrate-attached lipids, which are widely distributed throughout organisms and involved in the biosynthesis of glycoproteins and serve as ligands for toxins, lectins, bacteria, and viruses. In addition, sugars are also attached to the anomeric carbon of a non-sugar moiety via a glycosidic linkage, such as quinones, lactones, peptides, terpenoids, and alkaloids etc., performed by more than 80 families of glycosyl transferases and those secondary metabolites derive multiple drugs, such as gentamycin, vancomycin, bleomycin, and erythromycin etc. (Grynkiewicz et al., 2008; Yu et al., 2012). Although some glycosides are simply attached to saccharides and saccharide parts in which glycosides are mostly inactive in terms of activity, sometimes they are crucial for overall effects, such as the improvement of a drug's pharmacokinetics and/or dose-limiting toxicities and the improvement for a drug's solubility and selective/non-selective uptake into cells/organs of interest (Gantt et al., 2011; Yu et al., 2012).

Oceans cover more than $70 \%$ of the Earth's surface and host considerable diversity of species. Approximately 30,000 marine natural products had already been identified by the end of 2017 (Jimenez, 2018). The roles of marine natural products in biomedical research and drug development are significant and promising. Many marine natural products have been in clinical stages and the interest in marine natural products is increasing every year (Wang L. et al., 2018). Among these compounds, seven structural types of approved therapeutic agents are considered derivatives of marine natural products, including two nucleosides-the anticancer cytarabine (araC, FDA-approved in 1969) and the antiviral vidarabine (ara-A, FDA-approved in 1976)-derived from two natural arabinonucleosides (Figure 1) (Dyshlovoy and Honecker, 2018). Hence, glycosides have served as a validated platform for the development of many existing front-line drugs (Blanchard and Thorson, 2006). 

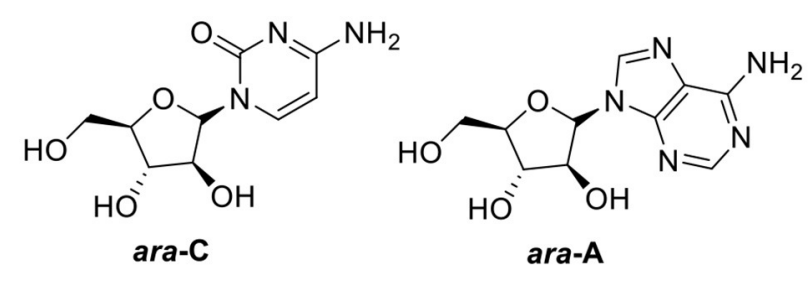

FIGURE 1 | Two FDA-approved nucleosides.

Given the vital role of glycosides in drug discovery, this review provides a comprehensive overview of the structures and biological activities of 205 glycosides (discovered 1997-2018) from marine-sourced bacteria, cyanobacteria, and fungi, along with the details of their source organisms.

\section{DISCUSSION}

\section{Marine-Sourced Bacteria Derived Natural Products \\ Quinones}

Four quinone-containing metabolites, halawanones A-D (1-4, Figure 2), have been isolated from Streptomycete sp. BD-18T(41) collected from shallow water sediment. The fraction containing halawanones A-B (1-2) exhibited inhibitory activity against Bacillus subtilis and Staphylococcus aureus at $100 \mu \mathrm{g} / \mathrm{disk}$, but did not inhibit Escherichia coli at $100 \mu \mathrm{g} /$ disk in a disk diffusion assay (Ford et al., 1998).

An anthracycline, komodoquinone A (5, Figure 2), with an amino sugar was isolated from the marine Streptomyces sp. KS3, derived from marine sediment. Komodoquinone A (5) was the first example of all anthracyclines and displayed neurogenic activity against a neuroblastoma cell line (Neuro 2A) at $1 \mu \mathrm{g} / \mathrm{ml}$ (Itoh et al., 2003). Four new anthracycline derivatives$\left(7 S^{*} 9 R^{*} 10 R^{*}\right)$-pyrromycin (6), $\left(7 R^{*} 9 R^{*} 10 R^{*}\right)$-pyrromycin (7), 1-hydroxyauramycin $\mathrm{T}(\mathbf{8})$, and 1-hydroxysulfurmycin $\mathrm{T}(\mathbf{9}$, Figure 2)-were given by a strain Streptomycete sp. (CANU Fox 21-2-6) isolated from the mouth of the Fox River. The bioactivity evaluation showed that all four compounds displayed considerable cytotoxicity against P388 cultured cells, with 50\% infectious dose $\left(\mathrm{ID}_{50}\right)$ values ranging from 0.4 to $0.06 \mu \mathrm{g} / \mathrm{ml}$ (Phipps et al., 2004). Two anthracyclines, 5-iminoaranciamycin (10) and tetracenoquinocin (11), were isolated from a culture broth of Streptomyces sp. Sp080513GE-26, originally derived from the marine sponge, Haliclona sp. Tetracenoquinocin (11) exhibited modest cytotoxicity in HeLa and HL-60 cells (IC50 120 and $210 \mu \mathrm{M}$, respectively) (Motohashi et al., 2010).

Further chemical investigation of the actinomycete Saccharothrix espanaensis An 113, associated with the marine mollusk Anadara broughtoni, led to the isolation of two angucyclines saccharothrixmicine A (12) and B (13, Figure 2). Bioassay results indicated that the saccharothrixmicinecontaining fraction exhibited activity toward Candida albicans and Xanthomonas sp. pv. Badrii (Kalinovskaya et al., 2008, 2010). Based on bioassay-guided analyses and the detection of genes encoding for the biosynthesis of secondary metabolites, the marine Streptomyces sp. strain HB202, which was isolated from the sponge Halichondria panacea, showed profound antibiotic activity and yielded a benz $[\alpha]$ anthracene derivative called mayamycin (14, Figure 2). This compound exhibited potent activity against several human cancer cell lines $\left(\mathrm{IC}_{50}\right.$ $0.15-0.33 \mu \mathrm{M})$ and inhibited growth of a number of bacteria including antibiotic-resistant strains ( $\left.\mathrm{IC}_{50} \quad 0.31-31.2 \mu \mathrm{M}\right)$ (Schneemann et al., 2010).

Arenimycin (15, Figure 2) from a strain Salinispora arenicola CNR-647 associated with ascidian Ecteinascidia turbinate showed significant activity against HCT-116 cells ( IC $\left._{50} 1.16 \mu \mathrm{g} / \mathrm{ml}\right)$. In addition, antibacterial testing with a panel of human Grampositive pathogens-including various MRSA strains, such as Enterococcus feacalis and Enterococcus faecium-showed that arenimycin (15) exhibited MIC values at or $<1 \mu \mathrm{g} / \mathrm{ml}$ (Asolkar et al., 2010). Isolated from the culture broth of Actinomadura sp., a polycyclic xanthone, IB-00208 (16, Figure 2), showed potent cytotoxic activity against several lines of human and murine tumor cell. Moreover, IB-00208 (16) exhibited considerable antibiotic activity against Gram-positive organisms (MIC 0.09$1.4 \mathrm{nM}$ ) (Malet-Cascon et al., 2003; Rodriguez et al., 2003). Pseudonocardians C (17, Figure 2), a diazaanthraquinone derivative, was produced by the strain SCSIO 01299, which is a marine actinomycete member of the genus Pseudonocardia and showed certain in vitro cytotoxic activities against the tumor cell lines, SF-268 (human glioma cell line), and MCF-7 (human breast adenocarcinoma cell line) with $\mathrm{IC}_{50}$ values of 6.70 and $8.02 \mu \mathrm{M}$, respectively (Li S. et al., 2011).

Gutingimycin (18, Figure 3) is a natural product with a trioxacarcin skeleton from Streptomyces B8652 isolated from a sediment (Maskey et al., 2002, 2004b). The same Streptomyces species also yielded trioxacarcins D-F (19-21, Figure 3) along with three known trioxacarcins, A-C. Bioactivity tests showed that trioxacarcins A-E exhibited strong antibacterial activity against a range of test organisms-including B. subtilis, Streptomyces viridoch-romogenes Tu 57, S. aureus, and E. coliwith MIC values of $0.15-2.5 \mu \mathrm{g} / \mathrm{ml}$, compared with the MIC values $>20 \mu \mathrm{g} / \mathrm{ml}$ for gutingimycin. In addition, an experiment against the large-cell lung cancer xenograft LXFL 529 in vitro indicated that the activity of trioxacarcin D (19) was similar to that previously reported for trioxacarcins A-C, with an $\mathrm{IC}_{50}$ value of $0.26 \mathrm{ng} / \mathrm{ml}$ (Maskey et al., 2004a). An unattainable bis-nitroglycosylated anthracycline, keyicin (22, Figure 3), was produced from coculturing of the producer Micromonospora strain with Rhodococcus. Biological activity indicated that it inhibited B. subtilis and methicillin-sensitive $S$. aureus (MSSA) with MIC values of $8 \mu \mathrm{g} / \mathrm{ml}(9.9 \mu \mathrm{M})$ and $2 \mu \mathrm{g} / \mathrm{ml}$ $(2.5 \mu \mathrm{M})$, respectively (Adnani et al., 2017). Six natural products with antibiotic activity-dechromose-A chromomycin $\mathrm{A}_{2}$ (23), dechromose-A chromomycin $\mathrm{A}_{3}$ (24), chromomycin $\mathrm{A}_{2}$ (25), chromomycin $\mathrm{A}_{3}(26)$, 4B-O-demethylchromomycin (27), and chromomycin $\mathrm{A}_{4}$ (28, Figure 3)-were found from the marine sediment-associated strain Streptomyces sp. KMM 9048. Among them, compounds $\mathbf{2 3}$ and $\mathbf{2 4}$ were established as chromomycin analogs. Antimicrobial activity showed that compounds 25, 26, and $\mathbf{2 7}$ were mostly active against $B$. subtilis at concentrations of $4.1,4.2$, and $4.3 \mu \mathrm{M}$, respectively. In addition, at a concentration 
<smiles>[R]c1cc(OC2CC(O)[C@H](O)[C@@H](O)C2)cc2c1C(=O)c1c(O)cccc1C2=O</smiles>

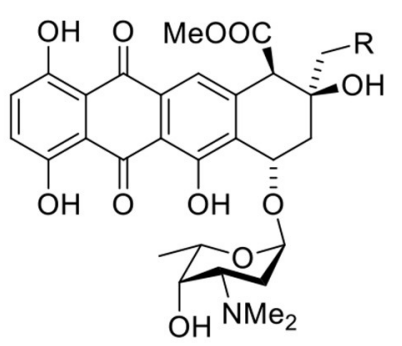
$1 \mathrm{R}=\mathrm{Me}$
$2 \mathrm{R}=\mathrm{Me}$

$$
4 \mathrm{R}=\mathrm{Et}
$$

\section{5}

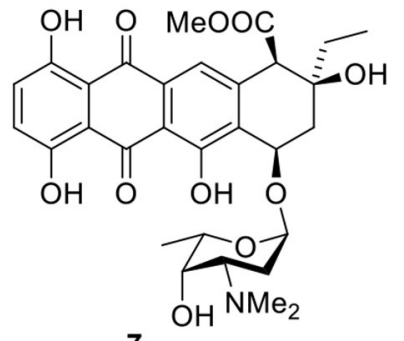

7

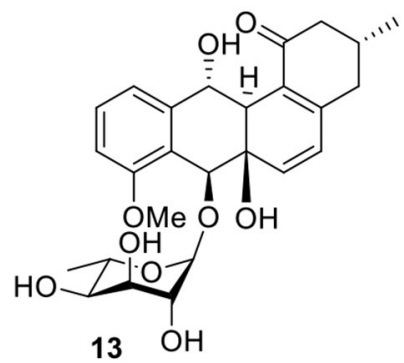

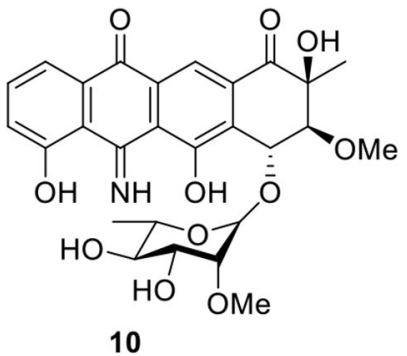

10<smiles>CN[C@@H]1C[C@@H](c2c(O)c3c(c4c(O)cc(C)cc24)C(=O)c2cccc(O)c2C3=O)O[C@@H](C)[C@H]1O</smiles>

14<smiles></smiles>

11<smiles>COC(=O)c1c(C)cc2c(c1O)[C@]1(O)C(=O)c3cc4c(c(O)c3C(=O)[C@@]1(OC)CC2)C(=O)C=C(NC1OC2O[C@@H]1C(O)C(O)C2O)C4=O</smiles>

15
$6 \mathrm{R}=\mathrm{Me}$

$8 \mathrm{R}=\mathrm{H}$<smiles></smiles>

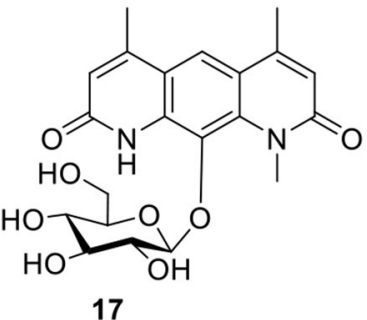

FIGURE 2 | Chemical structures of compounds 1-17 derived from marine-sourced bacteria.

of $5 \mathrm{nM}$, compound 25 exhibited strong inhibition of colony formation of human melanoma RPMI-7951 and SK-Mel-28 cells by 82 and 72\%, respectively (Kalinovskaya et al., 2017).

Three angucycline glycosides, designated grincamycins IK (29-31, Figure 3), were isolated from the marine-derived actinomycete, Streptomyces lusitanus SCSIO LR32. In antitumor tests in five human cancer cells-namely MDA-MB-435, MDAMB-231, NCI-H460, HCT-116, and HepG2-and human normal breast epithelial cell MCF10A cells, grincamycin J (30) showed cytotoxicity with $\mathrm{IC}_{50}$ values ranging from 2.6 to $5.4 \mu \mathrm{M}$; grincamycin I (29) showed strong cytotoxicity against MCF10A with an $\mathrm{IC}_{50}$ value of $2.9 \mu \mathrm{M}$; however, grincamycin $\mathrm{K}$ (31) did not exhibit cytotoxic activity. Structure-activity relationships suggested that classical angucyclines and the absence of the disaccharide at 3-O-position helped to enhance cytotoxic activity (Lai et al., 2018). With the application of the "Metal Stress" strategy for activating silent gene clusters, the Streptomyces pratensis strain NA-ZhouS1, isolated from marine sediment, produced two angucycline antibiotics stremycin A-B (32-33, Figure 3). The structures of $\mathbf{3 2}$ and $\mathbf{3 3}$ showed moderate antibiotic activities with equal MIC values of $16 \mu \mathrm{g} / \mathrm{ml}$ against Pseudomonas aeruginosa, MRSA, Klebsiella pneumonia, and 


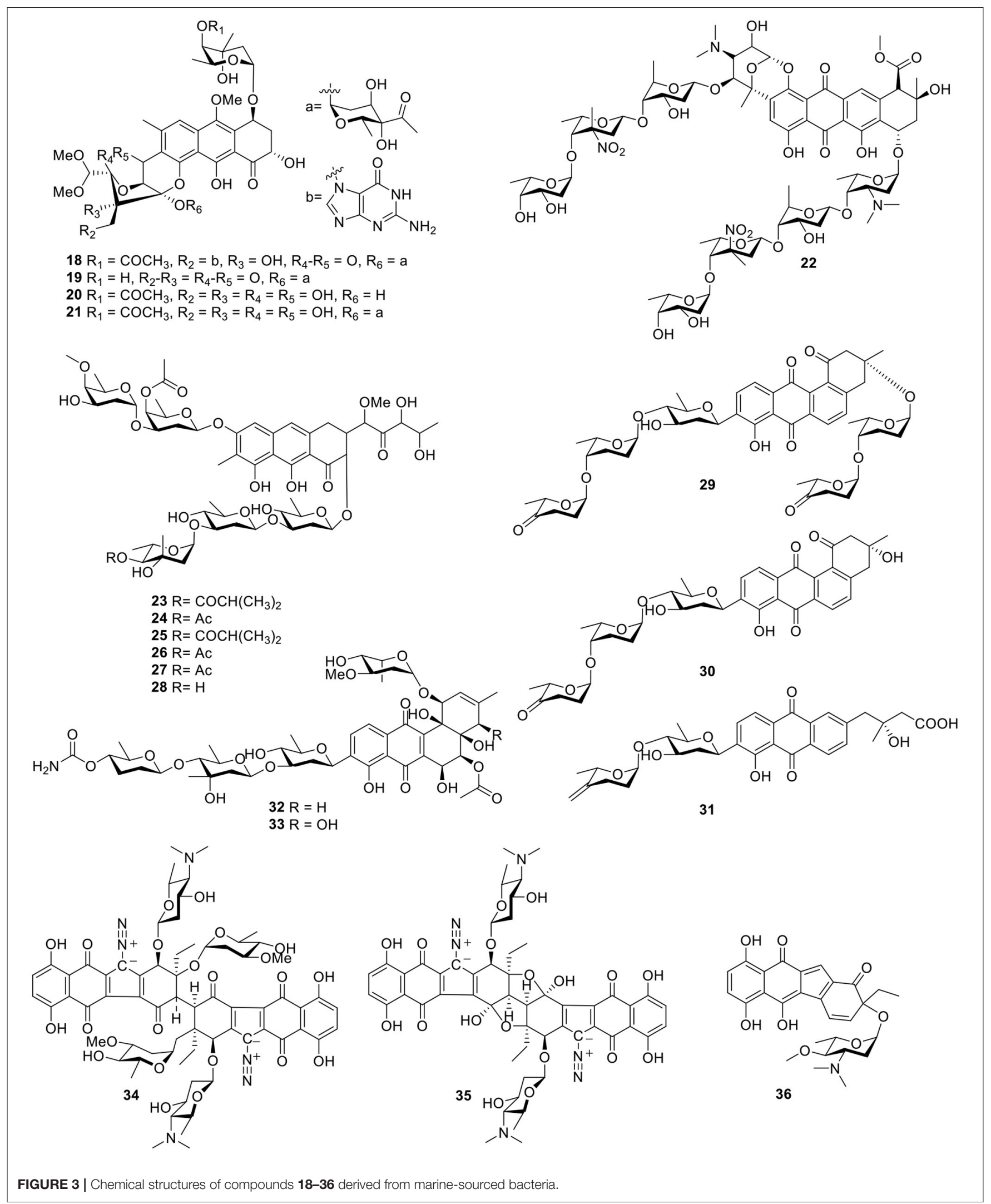


Escherchia coli. In addition, both compounds showed inhibition against B. subtilis at an MIC value of around $8-16 \mu \mathrm{g} / \mathrm{ml}$, respectively (Akhter et al., 2018).

Guided by a biochemical induction assay, two dimeric diazobenzofluorene glycosides, lomaiviticins A-B (34-35, Figure 3), were isolated from the halophilic actinomycete $L L$ 37I366, which was found to be a new species, Micromonospora lomaivitiensis. Both showed potent DNA-damaging activity at a minimum induction concentration $\leq 0.1 \mathrm{ng} / \mathrm{spot}$ and lomaiviticin A (34) exhibited cleaved double-stranded DNA under reducing conditions. In an assay against a number of cancer cell lines, lomaiviticin A (34) also possessed a unique cytotoxicity profile with $\mathrm{IC}_{50}$ values ranging from 0.01 to $98 \mathrm{ng} / \mathrm{ml}$ as compared to those of known DNA-damaging drugs, such as adriamycin and mitomycin C. Both lomaiviticins A-B (34-35) also exhibited potent antibiotic activity against $S$. aureus and E. faecium (He et al., 2001). Continuous searching for benzo $[b]$ fluorene led to the discovery of nenestatin A (36, Figure 3) produced from the deep sea-derived Micromonospora echinospora SCSIO 04089. Comparative bioinformatic analysis has indicated a high similarity of nenestatin A (36) and lomaiviticin gene clusters and has led to elucidation of similar biosynthetic pathways, including a conserved set of enzymes for the formation of a diazo group (Jiang X. et al., 2017).

\section{Macrocyclic Lactones}

With the application of bioassay-guided analyses, the macrolide antibiotic, chalcomycin B (37, Figure 4), was produced by the marine Streptomycete sp. B7064 derived from the mangrove sediment. Chalcomycin B (37) displayed activity against some microorganisms and microalgae (Asolkar et al., 2002). During the course of searching for bioactive secondary metabolites, the marine microbe Streptomycetes sp. strain HK-2006-1 from a marine sediment, produced six 16-membered macrolides, aldgamycins J-O (38-43, Figure 4), some of which exhibited strong antibacterial activity against S. aureus 209P, such as aldgamycins $\mathrm{M}-\mathrm{O}$ (41-43), which possessed MIC values of $16-32 \mu \mathrm{g} / \mathrm{ml}$. Structure-activity relationships showed that $\mathrm{OH}-8$ and the double bonds from $\mathrm{C}-10$ to $\mathrm{C}-13$ were beneficial for antibacterial activities (Wang et al., 2016). Further investigation for the Streptomycetes sp. strain HK-2006-1 led to a macrolide, chalcomycin E (44, Figure 4; Jiang S. et al., 2017). 7-O- $\alpha$-D-glucopyranoside (45, Figure 4), a macrolide with a rare $\alpha$-D-glucopyranose substituent, was isolated from marine actinomycete Pseudonocardia sp. HS7, originated from the cloacal aperture of sea cucumber Holothuria moebii. A bioassay test indicated that compound $\mathbf{4 5}$ displayed modest activity against cancer cell lines with $\mathrm{IC}_{50}$ values of 20.84$81.01 \mu \mathrm{M}$ (Ye et al., 2016). Further investigation for a strain of Streptomyces hygroscopicus OUPS-N92 obtained from the marine fish Halichoeres bleekeri led to a macrolide, halichoblelide (46, Figure 4), with potent cytotoxic activity against the murine P388 cell line and against 39 human cancer cell lines (Yamada et al., 2002). A glycosylated macrolide, macrolactin W (47, Figure 4), together with two known macrolides, macrolactins A and Q from the marine Bacillus sp. 09ID194 exhibited potent activity against B. subtilis (KCTC 1021), S. aureus (KCTC 1916), E. coli (KCTC
1923), and $P$. aeruginosa (KCTC 2592) with an MIC value of $64 \mu \mathrm{g} / \mathrm{ml}$ (Mondol et al., 2011).

Two derivatives of kijanimicin, lobophorins A-B (48-49, Figure 4), were produced from the fermentation broth of the marine actinomycete strain \# CNC-837 obtained from the surface of the Caribbean brown alga, Lobophora variegate, and both of them exhibited potent antiinflammatory activities in a Phorbol-Myristate-Acetate (PMA)-induced mouse ear edema model (Jiang et al., 1999). Another two analogs, lobophorins CD (50-51, Figure 4), produced by the actinomycete Streptomyces carnosus AZS17 obtained from marine sponges Hymeniacidon sp. Lobophorin C (50), displayed strong cytotoxic activity against the cellular proliferation of 7,402 hepatoma cells with an $\mathrm{IC}_{50}$ value of $0.6 \mu \mathrm{g} / \mathrm{ml}$. In addition, lobophorin D (51) had a potent inhibitory effect on the growth of the human breast cancer cell line, MDA-MB 435, with an $\mathrm{IC}_{50}$ value of $7.5 \mu \mathrm{M}$ (Wei et al., 2011). On the basis of bioassays, seven kijanimicin derivatives, microsporanates A-F (52-57) and tetrocarcin P (58, Figure 4), were isolated from the marine-derived Micromonospora harpali SCSIO GJ089. Among them, compounds 52-54 displayed vital growth-inhibiting activities against $B$. subtilis BS01 and Bacillus thuringiensis BT01, with MIC values of $0.016-0.5 \mu \mathrm{g} / \mathrm{ml}$, and compounds 55-58 exhibited moderate activities against $B$. subtilis BS01 and B. thuringiensis BT01 with MIC values of 1.0-8.0 $\mu \mathrm{g} / \mathrm{ml}$ (Gui et al., 2017).

\section{Lipids}

Two unique glycolipopeptides, ieodoglucomides A-B (59-60, Figure 5), were produced by the marine-derived bacterium Bacillus licheniformi and acted as broad spectrum, moderately active antimicrobial agents. In addition, ieodoglucomide B (60) displayed cancer growth inhibition against lung cancer (NCI-H23) and stomach cancer (NUGC-3) cell lines, with $\mathrm{GI}_{50}$ values of 25.18 and $17.78 \mu \mathrm{g} / \mathrm{ml}$, respectively (Tareq et al., 2012). Based on bioassay-guided purification, strain Pseudomonas BNT1, isolated from Antarctic sub-sea sediments, produced two rhamnolipids (61-62, Figure 5), and in an antibacterial experiment, compound $\mathbf{6 1}$ had the lowest MBC values against Burkholderia cenocepacia $(3.12 \mu \mathrm{g} / \mathrm{ml})$ and $S$. aureus $(3.12 \mu \mathrm{g} / \mathrm{ml})$ (Tedesco et al., 2016).

\section{Terpenoids}

A acyl glyco-carotenoic acid, diapolycopenedioic acid xylosyl ester (63, Figure 5), was produced from the marine bacterium Rubritalea squalenifaciens, belonging to the first subdivision of Verrucomicrobia and possessed potent antioxidative activity with an $\mathrm{IC}_{50}$ value of $4.6 \mu \mathrm{M}(10.9 \mu \mathrm{M}$ for $\beta$-carotene) (Shindo et al., 2007). Another three analogs, diapolycopenedioic acid xylosyl esters A-C (64-66, Figure 5), were obtained from the marine bacterium $R$. squalenifaciens, which was isolated from the marine sponge Halichondria okadai. Of the three compounds, compound 64 exhibited ${ }^{1} \mathrm{O}_{2}$ suppression activity with an $\mathrm{IC}_{50}$ of $5.1 \mu \mathrm{M}$ (Shindo et al., 2008a). With the same ${ }^{1} \mathrm{O}_{2}$ suppression activity as compound 64, methyl glucosyl-3, 4-dehydro-apo-8'-lycopenoate (67, Figure 5) was produced by the marine bacterium Planococcus maritimus strain iso-3 (Shindo et al., 2008b). 


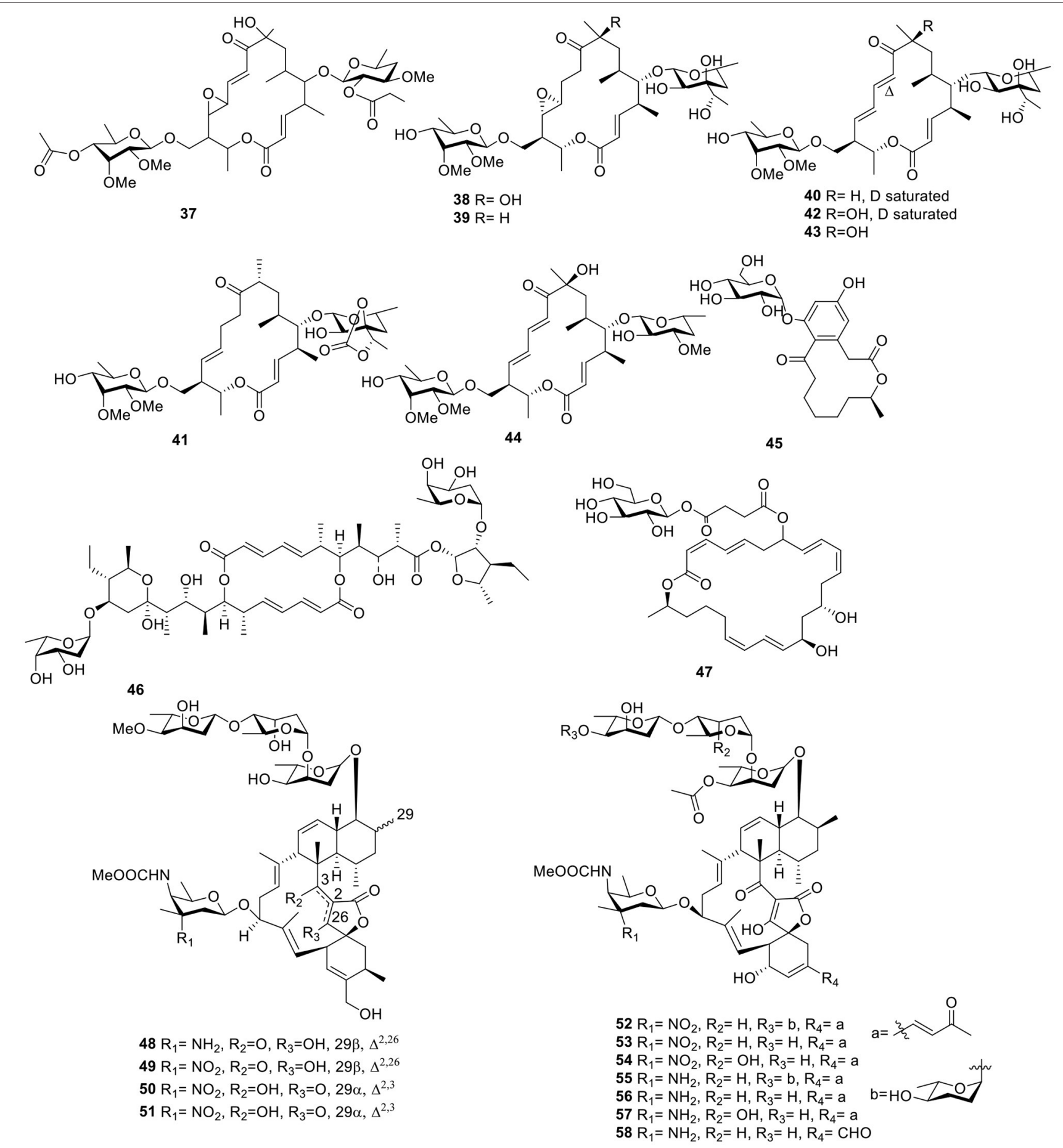

FIGURE 4 | Chemical structures of compounds 37-58 derived from marine-sourced bacteria

\section{Alkaloids}

Twelve indolocarbazoles 68-70, 71-76, and 77-79 (Figure 6) were isolated from the marine-derived Streptomyces sp. A68, Streptomyces sp. DT-A61, and Streptomyces sp. A65, respectively. Bioactivity testing showed that these indolocarbazoles had cytotoxic activities toward PC-3 cell lines with $\mathrm{IC}_{50}$ values of
0.8-41.3 $\mu \mathrm{M}$. In addition, most of these indolocarbazoles also showed potent kinase inhibitory activities against protein kinase $\mathrm{C}$ alpha $(\mathrm{PKC} \alpha)$, Roh associated protein kinase 2 (ROCK2), Bruton's tyrosine kinase (BTK), and apoptosis signal-regulating kinase 1 (AKS1). For instance, compound 7 displayed a notable inhibitory effect against ROCK2 with an $\mathrm{IC}_{50}$ value of $5.7 \mathrm{nM}$, 


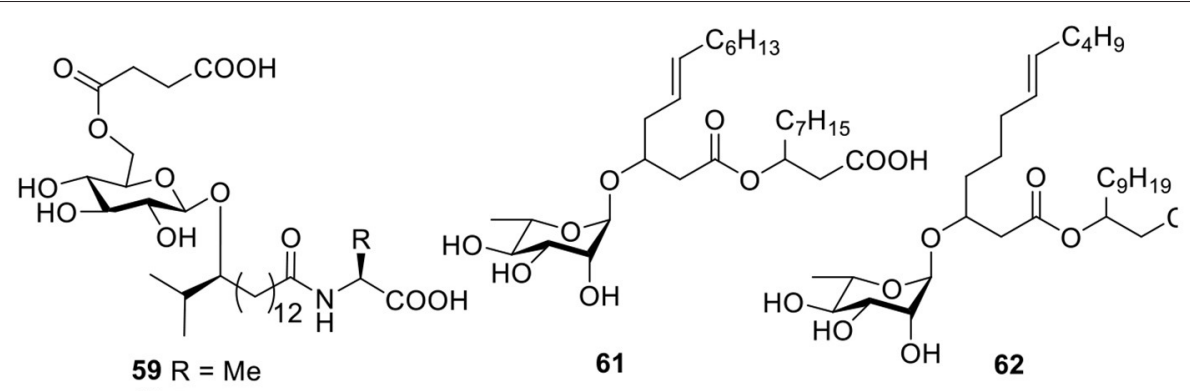

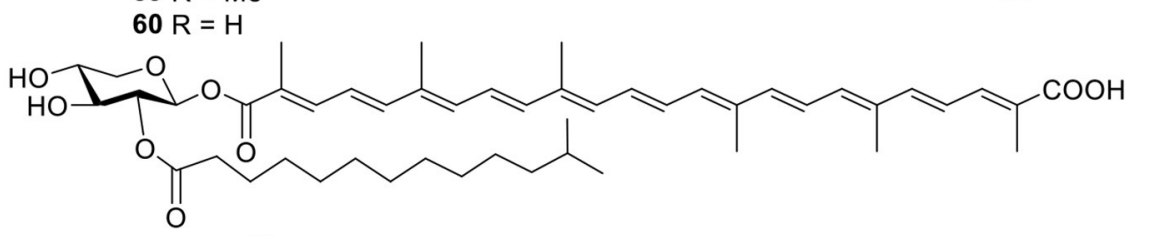

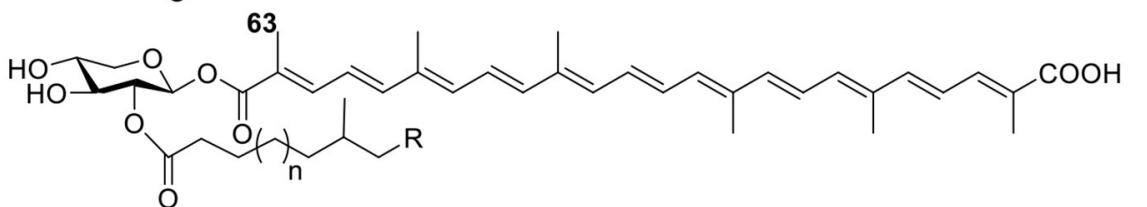

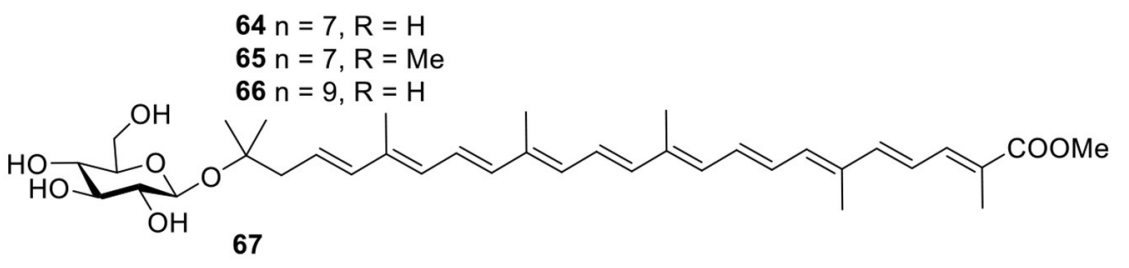

FIGURE 5 | Chemical structures of compounds 59-67 derived from marine-sourced bacteria.

which was similar to that of the positive control, staurosporine $\left(\mathrm{IC}_{50}=7.8 \mathrm{nM}\right)$. Structure-activity relationships for this set of indolocarbazoles suggested that when the sugar, connected with the K252c unit, was similar to that of staurosporine, the compound would be more effective than those without sugar moiety or those with only a single attachment of the sugar to the aromatic aglycone (Qin et al., 2018; Wang J. N. et al., 2018; Zhou et al., 2018).

Two rare $\mathrm{N}$-glycosyl indoles, kahakamides $\mathrm{A}-\mathrm{B}$ (80-81, Figure 6), were given by the actinomycete Nocardiopsis dassonvillei, isolated from a shallow water sediment sample. Bioassay testing indicated that kahakamide A (80) showed slight inhibition of B. subtilis in a disc-diffusion assay (Schumacher et al., 2001). From an actinomycete belonging to the family Nocardiopsaceae, Marinactinospora thermotolerans SCSIO 00652, methylpendolmycin-14-O- $\alpha$-glucoside (82, Figure 6) was identified and found to exhibit antiplasmodial activities against the Plasmodium falciparum lines $\mathrm{Dd} 2$ and $3 \mathrm{D} 7$ with $\mathrm{IC}_{50}$ values of 5.03 and $10.43 \mu \mathrm{M}$, respectively (Huang et al., 2011). One deoxyuridine (83, Figure 6), obtained from the Streptomyces microflavus strain, No. HVG29, represents the first example of acetyl deoxyuridine from marine-derived actinomycetes which was isolated from the marine sponge, Hymeniacidon perlevis (Li K. et al., 2011). Tunicamycin E (84, Figure 6), a new natural nucleoside antibiotic, was isolated from marine-derived Streptomyces xinghaiensis SCSIO S15077 and exhibited moderate antifungal activity against $B$. thuringiensis, $B$. thuringiensis, and C. albicans with MIC values of $2.0,0.5$, and $8.0 \mu \mathrm{g} / \mathrm{ml}$, respectively (Zhang et al., 2018).

A diketopiperazine glycoside, maculosin- $O-\alpha$-Lrhamnopyranoside (85, Figure 6), was obtained from a culture of the marine-derived actinomycete Streptomyces sp. ZZ446. Bioassay testing showed that compound $\mathbf{8 5}$ displayed antimicrobial activity against methicillin-resistant $S$. aureus, E. coli, and C. albicans with MIC values of $27.0-37.0 \mu \mathrm{g} / \mathrm{ml}$ (Chen et al., 2018). Cyanogrisides A-D (86-89, Figure 6) were four bipyridine cyclic glycosides from the actinomycete Actinoalloteichus cyanogriseus WH1-2216-6. Cyanogrisides A (86) and C (88) were moderately cytotoxic to three multidrug resistant (MDR) and drug-sensitive parental cell lines, and cyanogrisides $\mathrm{B}(\mathbf{8 7})$ reversed the multidrug resistance of K562/A02,MCF-7/Adr, and KB/VCR cells at a concentration of $10 \mu \mathrm{M}$, with reversal-fold values of $1.7,1.2$, and 3.6, respectively (Fu et al., 2011).

\section{Peptides}

Based on a multi-drug resistant E. faecium (MREF) assay, two thiazolyl peptide glycosides, nocathiacins I-II (90-91, Figure 7), were isolated from the cultured broth of Nocardia sp. WW-12651 (ATCC 202099). The nocathiacins exhibited strong in vitro activity against a broad spectrum of Grampositive bacteria, with MIC values of $0.1-60 \mathrm{ng} / \mathrm{ml}$. In addition, 


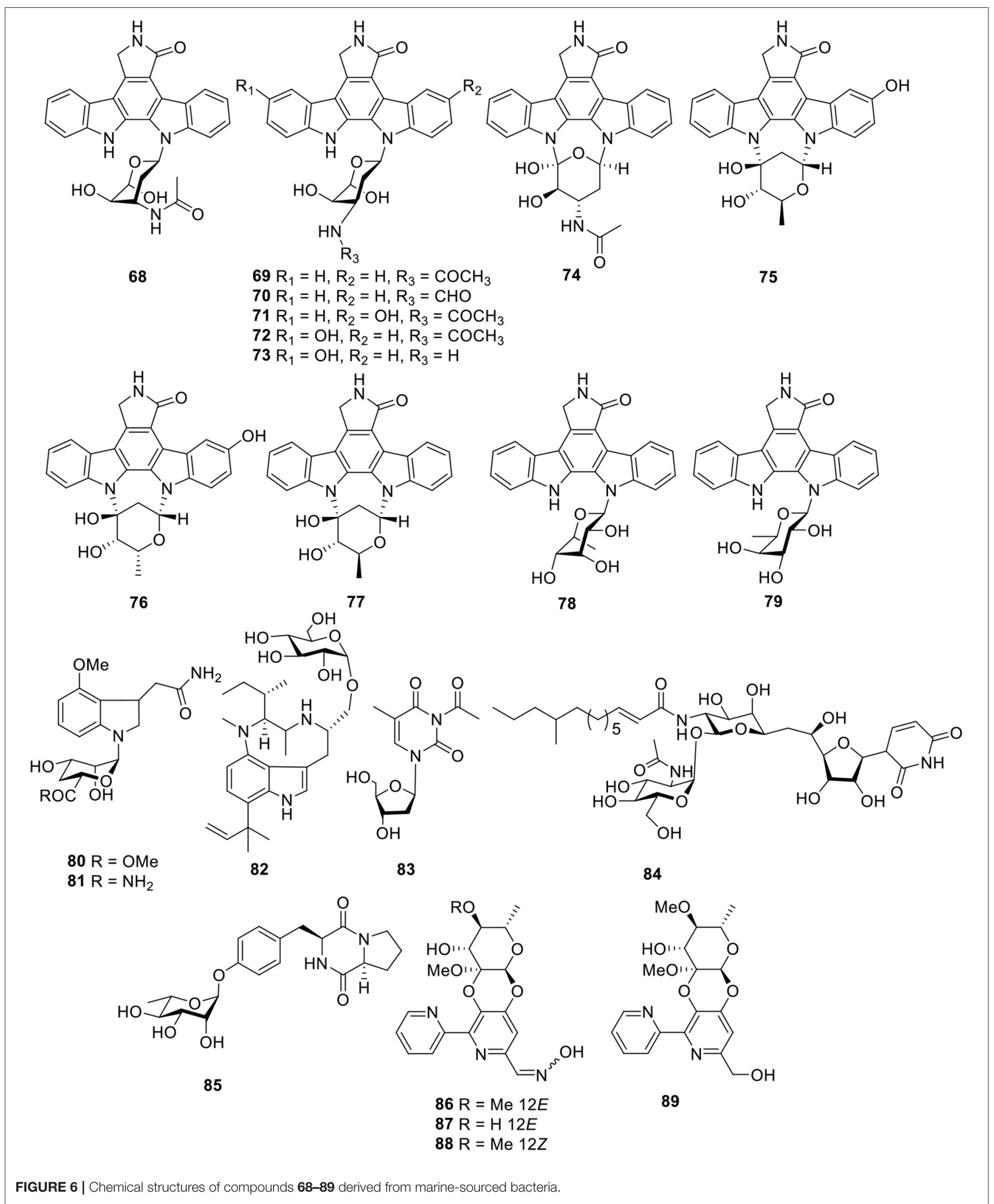


they also showed good in vivo efficacy in a systemic $S$. aureus infection mouse model (Leet et al., 2003; Li et al., 2003). One peptide-polyketide glycoside totopotensamide A (92, Figure 7) produced by a Streptomyces sp. 1053U.I.1a.1b, cultivated from the gastropod mollusk Lienardia totopotens, contains a previously undescribed 2,3-diaminobutyric acidcontaining macrolactam and an amino acid, 4-chloro-5,7-dihydroxy-6-methylphenylglycin (Lin et al., 2012).

\section{Other Classes}

A flavonoid-like glycoside, actinoflavoside (93, Figure 7), was detected in the culture broth of the marine Streptomyces sp. CNB-689 and showed only weak antibacterial activity against Gram-positive bacteria (Jiang et al., 1997). Further biological and chemical investigation of Salinispora strains led to the discovery of a third species with this genus, Salinispora pacifica, which produced two chlorinated cyclopenta $[\alpha]$ indene glycosides, cyanosporasides A-B (94-95, Figure 7; Oh et al., 2006). Isolated from the marine actinomycetes Micromonospora matsumotoense M-412, the first compound of the paulomycin family lacking the paulomycose structure, paulomycin G (96, Figure 7), displayed excellent cytotoxic activities against several human tumor cell lines_such as MiaPaca_2, MCF-7, and HepG2 - with IC $_{50}$ values of $2.70,1.58$, and $4.30 \mu \mathrm{M}$, respectively (Sarmiento-Vizcaino et al., 2017).

Two antitumor pyranone glycosides, PM050511 (97) and PM0060431 (98, Figure 7), along with their aglycones PM050463 and PM060054, were obtained from the marine-derived Streptomyces albus, POR-04-15-053. Bioassay testing suggested that compounds 97-98 showed excellent cytotoxicity against three human tumor cell lines with $\mathrm{GI}_{50}$ values in the range of 0.24-2.69 $\mu \mathrm{M}$ (Schleissner et al., 2011). A cytotoxic piericidin derivative, glucopiericidin C (99, Figure 7), was isolated from the marine-derived Streptomyces species B8112 and showed a concentration-dependent cytotoxicity toward a panel of 36 human tumor cell lines with an $\mathrm{IC}_{50}$ value of $2.0 \mu \mathrm{M}$ (mean $\mathrm{IC}_{70}=4.2 \mu \mathrm{M}$ ), in addition to the same antibacterial activity as glucopiericidin A (Shaaban et al., 2011). One flavonoid derivative, flavoside A (100, Figure 7), was produced from the EtOAc extract of the culture broth of the sea urchin (Anthocidaris crassispina)-derived actinobacterium, Streptomyces sp. HD01 (Guo et al., 2019). According to the HPLC-UV profile, the Streptomyces sp. CMN-62 isolated from an unidentified sponge sample was selected for its chemical investigation and produced two anthranilate-containing alkaloids, anthranosides A-B (101102, Figure 7; Che et al., 2018). Chemical analysis of these actinomycete strains using LC/MS identified a Streptomyces sp. SNM31 and led to a metabolite, mohangic acid E (103, Figure 7), which was the first glycosylated compound discovered in the $p$ aminoacetophenonic acid family and exhibited good quinonereductase induction activity at a concentration of $20 \mu \mathrm{M}$ (Bae et al., 2016).

\section{Marine-Sourced Cyanobacteria Derived Natural Products \\ Macrocyclic Lactones}

Lyngbya bouillonii Hoffmann and Demoulin is a "superproducer," which is a filamentous, non-heterocystous, blue-green alga up to $50 \mu \mathrm{m}$ wide (Klein et al., 1997). Guided by cancer viability assays and the aid of LC-MS, six macrolide glycosides-lyngbyaloside (104), lyngbyaloside B (105), lyngbouilloside (106), 2-epi-lyngbyaloside (107), and the regioisomeric 18E- and 18Z-lyngbyalosides C (108-109, Figure 8)-were isolated from $L$. bouillonii. Bioassay testing suggested that lyngbyaloside B (105) exhibited weak cytotoxicity against $\mathrm{KB}$ cells, with an $\mathrm{IC}_{50}$ value of $4.3 \mu \mathrm{M}$ and showed a smaller effect on LoVo cells $\left(\mathrm{IC}_{50} \approx 15 \mu \mathrm{M}\right)$; additionally, lyngbouilloside (106) was only moderately cytotoxic to neuro-2a neuroblastoma cells $\left(\mathrm{IC}_{50}=17 \mu \mathrm{M}\right)$ (Klein et al., 1997; Luesch et al., 2002; Tan et al., 2002; Matthew et al., 2010).

Bioassay-guided investigation of the marine cyanobacterium Lyngbya sp., collected in Okinawa Prefecture, led to an 18membered macrolide glycoside, biselyngbyaside (110, Figure 8). Biselyngbyaside (110) exhibited broad-spectrum cytotoxicity in a panel of human tumor cell lines and likely inhibited cancer cell proliferation through a mechanism indicated by COMPARE analyses (Teruya et al., 2009). Chemical investigation of the marine cyanobacterium Lyngbya sp., collected from the Tokunoshima Island, Japan, led to three new analogs of biselyngbyaside (110), biselyngbyasides B-D (111-113, Figure 8). Biselyngbyaside B (111) was shown to induce apoptosis in $\mathrm{HeLa} \mathrm{S}_{3}$ cells and HL60 cells. Further investigation of this activity in HeLa $S_{3}$ cells indicated that apoptosis is likely mediated through increasing cytosolic $\mathrm{Ca}^{2+}$ concentrations (Morita et al., 2012).

The dimeric macrolide xylopyranoside, cocosolide (114, Figure 8), was obtained from the marine cyanobacterium preliminarily identified as Symploca sp. and reduced IL2 production without significantly affecting cell viability. Comparison of the activities of analogs indicated the importance of sugars and dimeric structures to the target recognition and engagement process (Gunasekera et al., 2016). Bioassay-guided fractionation of the extract of Leptolyngbya sp., collected from the coast of Itoman City in the Okinawa Prefecture (Japan), led to the separation of two macrolactones, leptolyngbyolides A-B (115-116, Figure 8), both of which showed strong growth inhibition against $\mathrm{HeLa} \mathrm{S}_{3}$ cells with $\mathrm{IC}_{50}$ values of 0.1 and $0.16 \mu \mathrm{M}$, respectively. In addition, structure-activity relationships suggested that the sugar moiety did not affect growth-inhibitory activity (Cui et al., 2017).

The polycavernoside analog, polycavernoside D (117, Figure 9), was isolated from a red-colored Okeania sp. and had moderate activity against the human lung carcinoma cell line $\mathrm{H}$ $460\left(\mathrm{EC}_{50}=2.5 \mu \mathrm{M}\right)$. Importantly, polycavernoside D (117) was obtained from the Atlantic, whereas polycavernosides previously isolated were derived from the Western Pacific, suggesting that these toxins occur over a much wider geographical range than originally thought (Navarro et al., 2015). Two glycosylated swinholides, ankaraholides A-B (118-119, Figure 9), were produced by the cyanobacterium, Geitlerinema sp., from a Madagascar field collection. Bioassay testing indicated that ankaraholide A (118) inhibited proliferation (IC 50 values) in NCI-H460 (119 nM), Neuro-2a (262 nM), and MDA-MB-435 (8.9 nM) cell lines (Andrianasolo et al., 2005). Under bioassay-guided separation in combination with the MS2-based molecular-networking dereplication tool, 


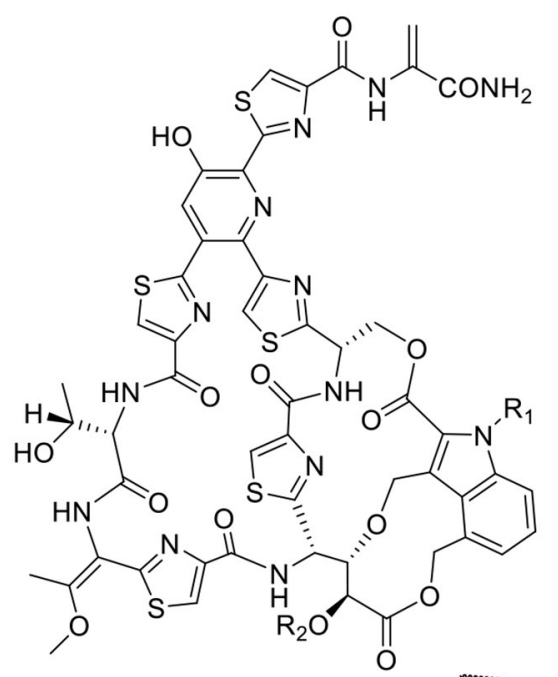

$90 \mathrm{R}_{1}=\mathrm{OH}, \mathrm{R}_{2}=\underset{\substack{\mathrm{HO} \\ \mathrm{NMe}_{2}}}{\mathrm{HO} J^{m}}$

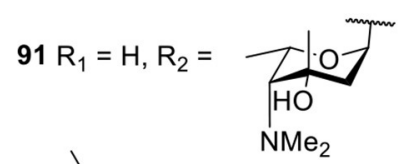

93<smiles>CCOc1cc(CO)c2c(c1O)OC(c1ccccc1)CC2=O</smiles>

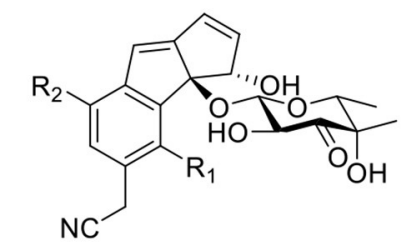

$94 \mathrm{R}_{1}=\mathrm{Cl}, \mathrm{R}_{2}=\mathrm{H}$

$95 \mathrm{R}_{1}=\mathrm{H}, \mathrm{R}_{2}=\mathrm{Cl}$<smiles>C/C=C(/N=C=S)C(=O)OCC(CC)OC(=O)C1(O)OC(=O)C(N)=C(C(=O)O)C1=O</smiles>

96<smiles>[R20]OC(/C(C)=C/C)C(C)/C=C(C)/C=C/CC(C)/C=C/c1oc(OC)c([R16])c(=O)c1C</smiles>

$97 \mathrm{R}_{1}=\mathrm{Me}, \mathrm{R}_{2}=\mathrm{HO}_{\mathrm{HO}}^{\mathrm{HO}}$

99

$98 R_{1}=E t, R_{2}={ }_{\mathrm{HOH}}^{\mathrm{HO}_{\mathrm{O}}}$<smiles>COc1cc(-c2cc(=O)c3c(O)cc(O)cc3o2)cc(OC)c1OC1OC2C(O)C(O)C(O)C2O1</smiles><smiles>C/C=C/C(=O)C[C@H](O)CCCC(O)C/C=C/C=C/C=C/C(O)CC(C)=O</smiles>

FIGURE 7 | Chemical structures of compounds $\mathbf{9 0 - 1 0 3}$ derived from marine-sourced bacteria. 


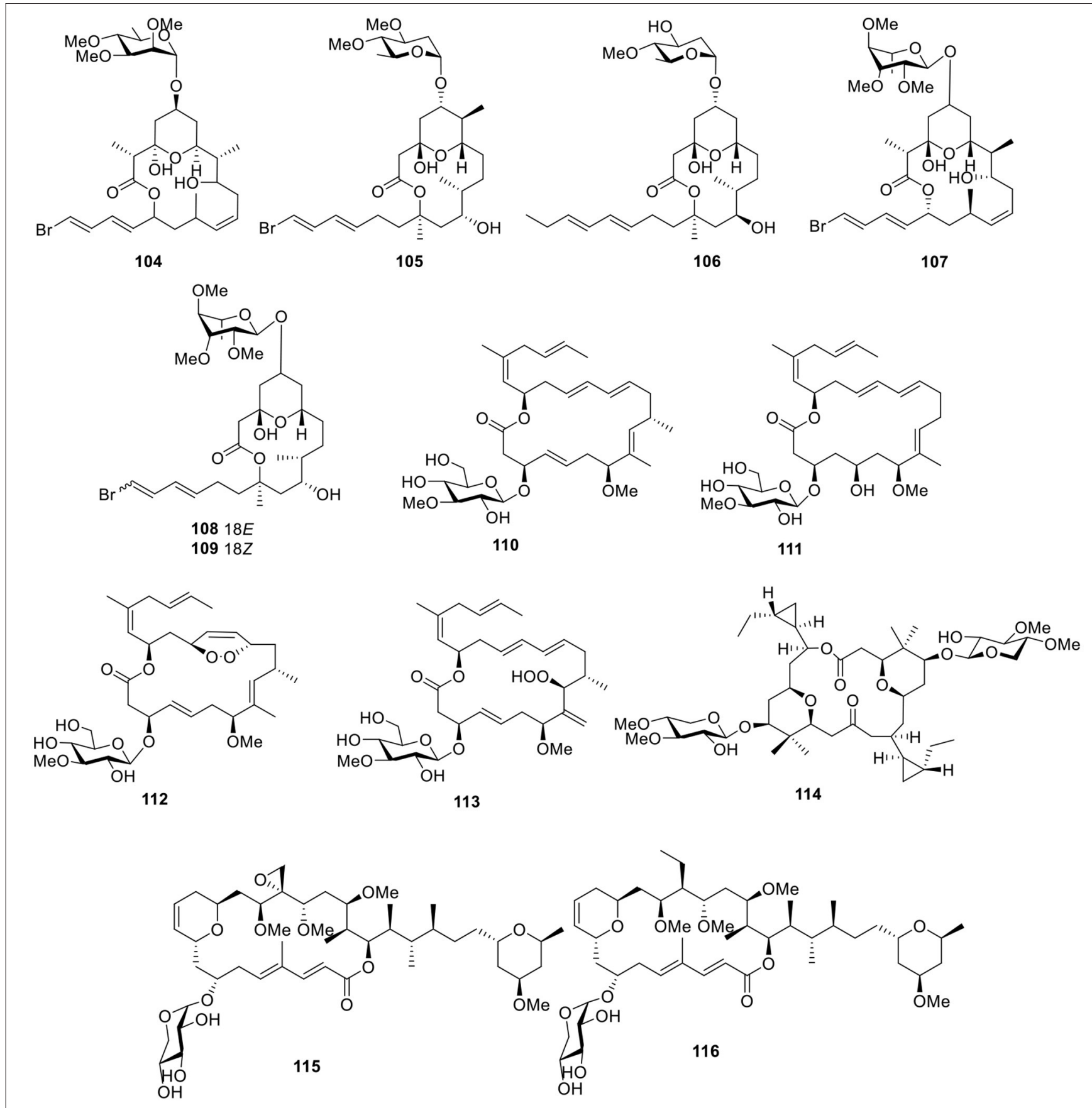

FIGURE 8 | Chemical structures of compounds 104-116 derived from marine-sourced cyanobacteria.

nine glycosylated swinholide-type compounds, samholides A-I (120-128, Figure 9), were separated from the American Samoan marine cyanobacterium cf. Phormidium sp. All of these samholides showed potential activities against the human lung cancer cell line $\mathrm{H}-460$ with $\mathrm{IC}_{50}$ values ranging from 170 to $910 \mathrm{nM}$. Comparison of the activities of these samholides suggested that the sugar and glycericacid units played important roles in enhancing the cytotoxic activity (Tao et al., 2018).

\section{Lipids}

Further investigation of the marine cyanobacterium Lyngbya majuscula from Curafao yielded one glycoside metabolite, malynsamide J (129, Figure 10). Bioassay testing suggested that malynsamide J (129) was toxic to both brine shrimp and fish (Wu et al., 1997). Bartolosides A-D (130-133, Figure 10), which are unique glycolipids featuring aliphatic chains with chlorine substituents and C-glycosyl parts, were isolated from the filamentous cyanobacterium Nodosilinea sp. 

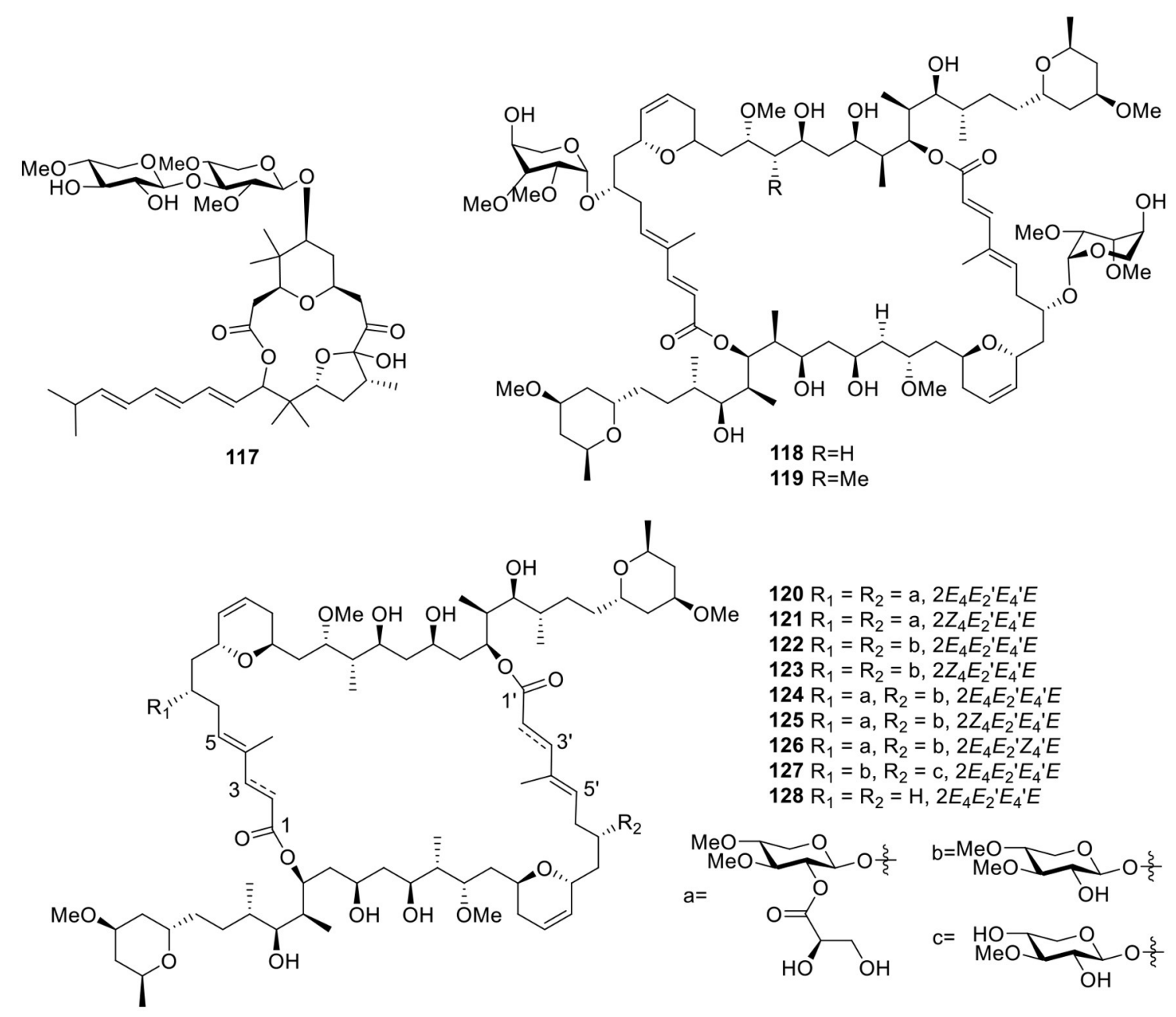

FIGURE 9 | Chemical structures of compounds 117-128 derived from marine-sourced cyanobacteria.

LEGE 06102 and Synecho-cystis salina LEGE 06155, respectively. The determination of the planar structure of bartolosides through key pathway intermediates illustrates the importance of genomics for structure elucidation. In addition, the biosynthesis of the diglycosylated dialkylresorcinol skeleton of bartolosides B-D (131-133) involves first the head-to-head condensation of an $\alpha, \beta$-unsaturated fatty acyl-ACP thioester with a $\beta$-keto-fatty acyl-ACP thioester, catalyzed by the ketosynthase, BrtD (Leao et al., 2015). Another seven analogs, bartolosides E-K (134-140, Figure 10), produced from Synechocystis salina LEGE 06099, a strain closely related to the Synecho-cystis salina LEGE 06155 and bartoloside E (134), showed antitumor activities against the MG-63, RKO, and T-47D cell lines with $\mathrm{IC}_{50}$ values of 39,40 , and $22 \mu \mathrm{M}$, respectively (Afonso et al., 2016). One cerebroside, mooreaside A (141, Figure 10), was produced by the marine cyanobacterium Moorea producens, collected from the Red Sea and displayed moderate activity toward the MCF-7 cancer cell line with an $\mathrm{IC}_{50}$ value of $20.5 \mu \mathrm{M}$ (Youssef et al., 2016).

\section{Alkaloids}

Chemical investigation of the crude organic extract of $L$. majuscula from Puerto Rico resulted in the quinoline alkaloid 142 (Figure 10), the geometry of which was established as $(E)$ by ${ }^{1} \mathrm{H}_{-}{ }^{13} \mathrm{C}$ coupling constant measurements from HSQMBC NMR experiments (Nogle and Gerwick, 2003). Except for the mooreaside A (141), the marine cyanobacterium $M$. producens also yielded two nucleoside derivatives, 3 -acetyl- $2^{\prime}$-deoxyuridine (143) and 3-phenylethyl-2'-deoxyuridine (144, Figure 10), both of which showed moderate activity toward the MCF-7 cancer cell line with $\mathrm{IC}_{50}$ values of 18.2 and $22.8 \mu \mathrm{M}$, respectively (Youssef et al., 2016).

\section{Marine-Sourced Fungi Derived Natural Products Quinones}

A anthracene glycoside, asperflavin ribofuranoside (145, Figure 11), was isolated from the marine-derived fungus Microsporum sp. Compound 145 showed radical scavenging 

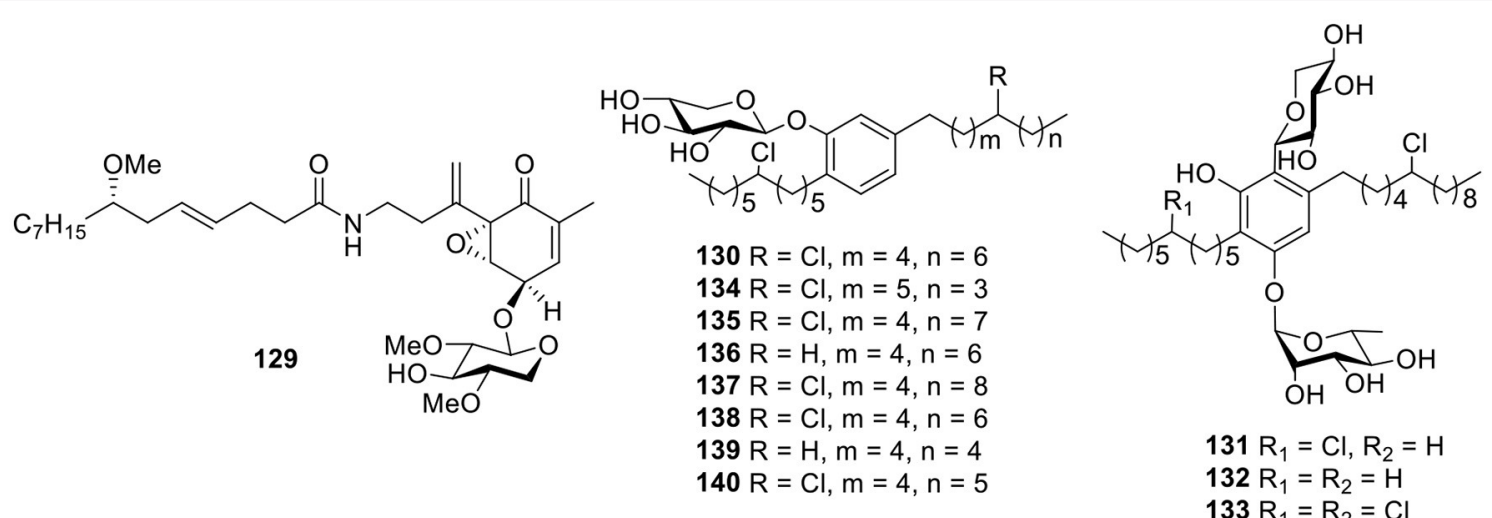

$$
\begin{aligned}
& 131 \mathrm{R}_{1}=\mathrm{Cl}, \mathrm{R}_{2}=H \\
& 132 \mathrm{R}_{1}=\mathrm{R}_{2}=\mathrm{H} \\
& 133 \mathrm{R}_{1}=\mathrm{R}_{2}=\mathrm{Cl}
\end{aligned}
$$

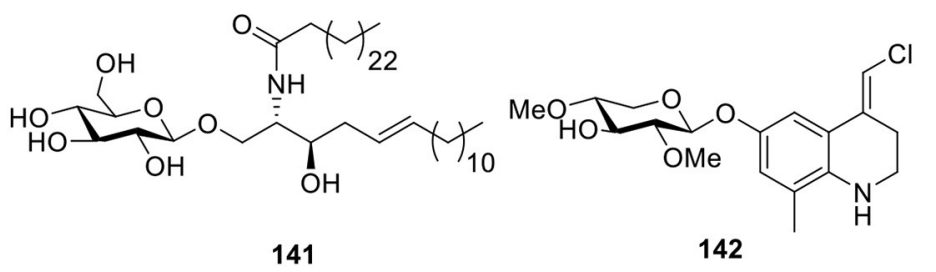

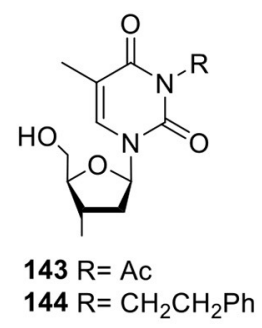

FIGURE 10 | Chemical structures of compounds 129-144 derived from marine-sourced cyanobacteria.

activity against $\mathrm{DPPH}$ with an $\mathrm{IC}_{50}$ value of $14.2 \mu \mathrm{M}$ and also exhibited moderate antibacterial activity against the methicillinresistant and multidrug-resistant $S$. aureus with an MIC value of $50.0 \mu \mathrm{g} / \mathrm{ml}$ ( $\mathrm{Li}$ et al., 2006). The xanthone O-glycoside, 3-O-(6-O- $\alpha$-L-arabinopyranosyl)- $\beta$-D-gluco- $\quad$ pyranosyl-1,4dimethoxyxanthone (146, Figure 11), was obtained from the mangrove endophytic fungus Phomopsis sp. ZH76 and was found to display cytotoxicity against HEp-2 and HepG2 cells with $\mathrm{IC}_{50}$ values of 9 and $16 \mu \mathrm{mol} / \mathrm{ml}$, respectively (Huang et al., 2013). In the assessment of a library of marine-derived fungi (240 strains) for growth inhibitory activity against Mycobacterium phlei ( $M$. phlei), the extract of the sponge-derived fungus Metarhizium anisopliae mxh-99 displayed promising levels of anti-M. phlei activity and produced two naphtho- $\gamma$-pyrones glycosides, indigotides G-H (147-148, Figure 11; Kong et al., 2013).

\section{Esters}

The 3,4-dihydroisocoumarin derivative, $\mathrm{R}-(-)$-mellein-8- $O-\beta$-Dglucopyranoside (149, Figure 11), was yielded from the marinederived fungus Paraconiothyrium sporulosum YK-03 (Zhang et al., 2017). Another two isocoumarin glucosides, halorosellins A-B (150-151, Figure 11), were produced from a culture broth of the marine fungus, Halorosellinia oceanica $187 q$ BCC 5149 (Chinworrungsee et al., 2002). Based on bioassay test, another two isocoumarin derivatives, acremonones $H$ (152), and penicimarins D (153, Figure 11), were produced from the mangrove-derived fungus Acremonium sp. PSU-MA70 and the sponge-derived fungus, Penicillium sp. MWZ14-4, respectively (Rukachaisirikul et al., 2012; Qi et al., 2013). One mycophenolic acid derivative, penicacid B (154, Figure 11), was given by a fungus, Penicillium sp. SOF07 derived from a marine sediment in the South China Sea and was found to inhibit inosinemonophosphate dehydrogenase (IMPDH) (Chen et al., 2012). The marine-derived fungus Cosmospora sp. SF-5060, isolated from inter-tidal sediment, produced the depside derivative, aquastatin A (155, Figure 11). Aquastatin A was found to display potent selective inhibitory activity against protein tyrosine phosphatase $1 \mathrm{~B}$ (PTP1B) with an $\mathrm{IC}_{50}$ value of $0.19 \mu \mathrm{M}$ in a competitive manner (Seo et al., 2009). Another $C$-glycosidic depside, stromemycin (156, Figure 11), was identified from the crude extract of the fungus Emericella variecolor derived from the marine sponge Haliclona valliculata (Bringmann et al., 2003).

\section{Lipids}

Two cerebroside analogs, flavicerebrosides A and B (157-158, Figure 12), were obtained from the cultivated mycelium of the marine-derived fungus Aspergillus flavipes, isolated from the sea anemone Anthopleura xanthogrammica and exhibited cytotoxic activity against the $\mathrm{KB}$ cell line with $\mathrm{IC}_{50}$ values of 20.1 and $14.3 \mu \mathrm{g} / \mathrm{ml}$, respectively (Jiang et al., 2004). The Quanzhou marine fungus Aspergillus niger (MF-16) produced another two cerebrosides, asperiamides B and C (159-160, Figure 12; Wu et al., 2008). With the constant effort to isolate microbes from hypersaline environments, the marine-derived halotolerant fungal strain (THW-18), Alternaria raphani, was isolated and afforded three cerebrosides, alternarosides $\mathrm{A}-\mathrm{C}$ (161-163, Figure 12). Bioassay testing indicated that compounds 161-163 showed small antibacterial activity against E. coli, $B$. subtilis, and C. albicans (Wang et al., 2009). Flavusides A-B (164165, Figure 12), two new antibacterial cerebroside derivatives, 
<smiles>COc1cc(OCC2OC3OC2C3O)cc2cc3c(c(OC)c12)C(=O)C[C@@H](O)C3</smiles>

145

146

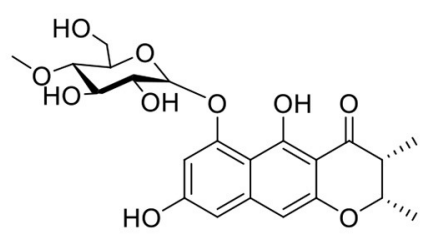

147<smiles>[R6]c1cc(OC2OC(O)C(O)C(O)C2O)c2c(c1C)C(C)C(=C)OC2=O</smiles>

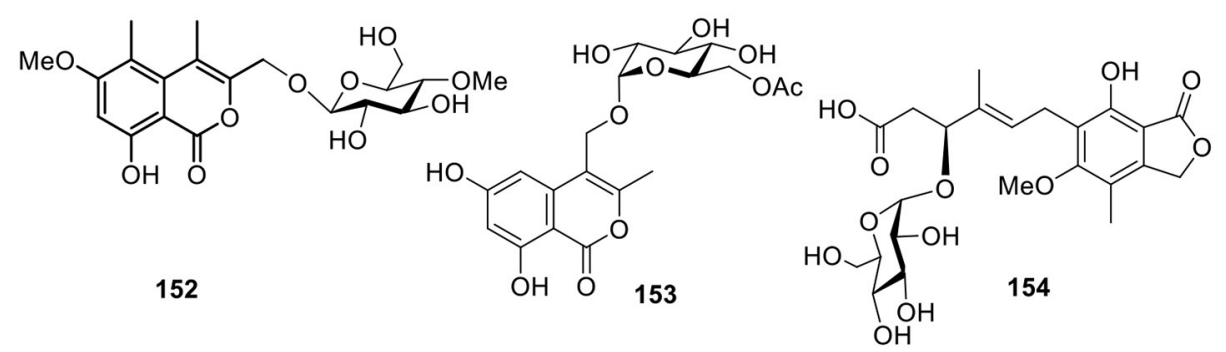

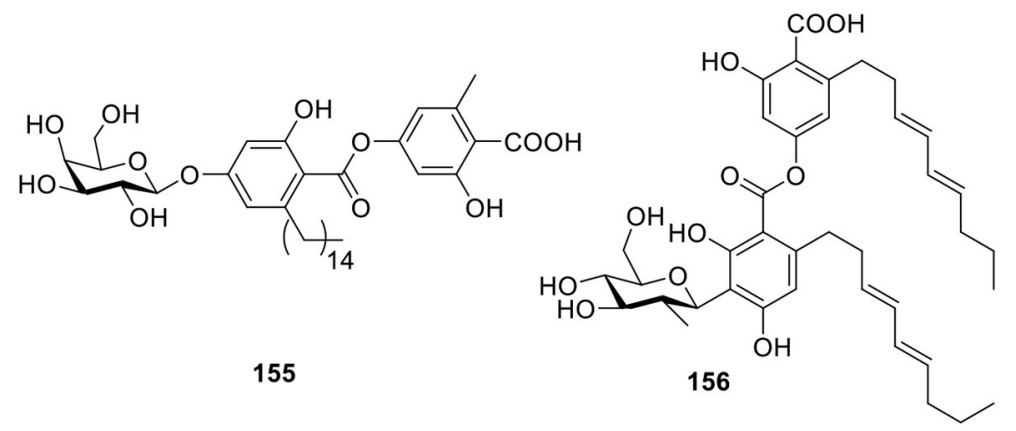

FIGURE 11 | Chemical structures of compounds 145-156 derived from marine-sourced fungi.

were identified from the fermentation broth of the marinederived fungus Aspergillus flavus and showed weak inhibitory activities against $S$. aureus and methicillin-resistant $S$. aureus (Yang et al., 2011).

In order to explore bromodomains (BRD) inhibitors, the secondary metabolites of Alternaria sp. NH-F6, a fungus obtained from deep-sea sediment samples, were analyzed and led to a cerebroside (166, Figure 12) along with two perylenequinones (Ding et al., 2017). Under continuous searching for bioactive natural products from Red-Sea marine-derived fungi, the fungus Penicillium was isolated from the tunicate Didemnum and led to two cerebrosides, penicillosides A-B (167-168, Figure 12). In an agar diffusion assay, penicilloside A (167) exhibited antifungal activity against
C. albicans, while penicilloside B (168) showed antibacterial activities against S. aureus and E. coli (Murshid et al., 2016). Four highly methylated glycolipids-roselipins 1A (169), 1B (170), 2A (171), and 2B (172, Figure 12)-were obtained from the marine fungus Gliocladium roseum KF-1040. In an enzyme assay system using rat liver microsomes, roselipins inhibited the enzyme, diacylglycerol acyl transferase (DGAT) with $\mathrm{IC}_{50}$ values of 17-22 $\mu \mathrm{M}$ (Omura et al., 1999; Tabata et al., 1999). One fatty acid, glucoside (173, Figure 12), was isolated from the endophytic fungus A1 of mangrove plant, Scyphiphora hydrophyllacea Gaertn. F. Through using a filter-paper disc-agardiffusion method, compound $\mathbf{1 7 3}$ possessed modest inhibitory activity on Staphylococcus aureus and methicillin-resistant $S$. aureus (Zeng et al., 2012). 


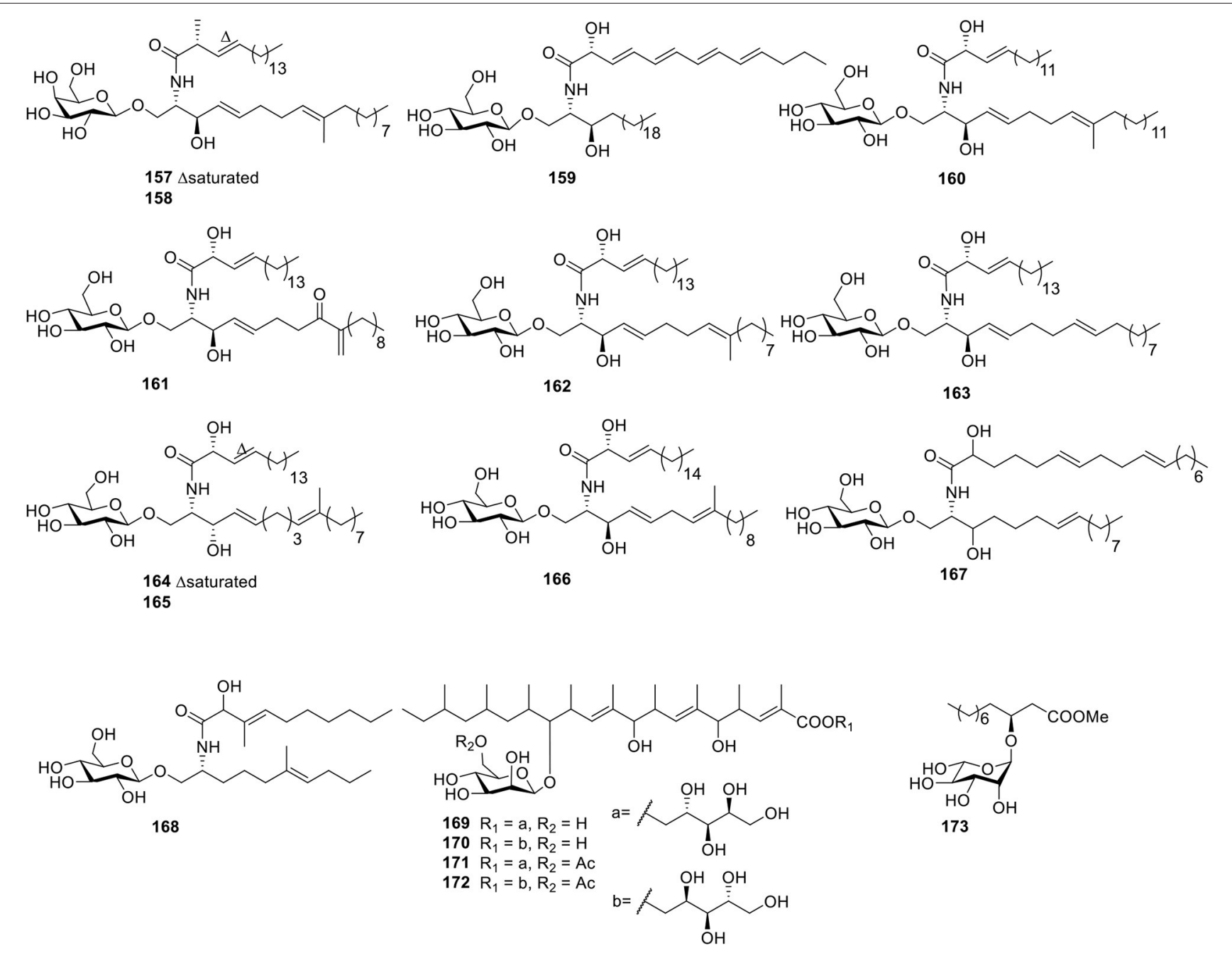

FIGURE 12 | Chemical structures of compounds 157-173 derived from marine-sourced fungi.

\section{Terpenoids}

The fungus Acremonium striatisporum was originally obtained from the holothurian Eupentacta fraudatrix, and multiple investigations for metabolites of this strain led to the isolation of 21 glycosides, namely virescenosides $M-X$ (174-185), Z (186), $\mathrm{R}_{1}-\mathrm{R}_{3}$ (187-189), and $\mathrm{Z}_{4}-\mathrm{Z}_{8}$ (190-194, Figure 13). Bioassay testing showed that virescenosides $M-U$ (174-182) displayed cytotoxic action against tumor cells Ehrlich carcinoma $\left(\mathrm{IC}_{50}=\right.$ $10-100 \mu \mathrm{M})$ in vitro. In addition, virescenosides $\mathrm{M}-\mathrm{N}$ (174175) and $P$ (177) displayed cytotoxic effects on developing eggs of the sea urchin, Strongylocentrotus intermedius $\left(\mathrm{IC}_{50}=\right.$ 2.7-20 MM) (Afiyatullov et al., 2000, 2002, 2004, 2006, 2011, 2016). Two phenylspirodrimane-type glucosidic meroterpenoids, stachybosides A-B (195-196, Figure 13), were seperated from the sponge-derived fungus, Stachybotrys chartarum MXH-X73 (Ma et al., 2013). The polyketide glycoside, cladionol A (197, Figure 13), was produced from the culture broth of the fungus Gliocladium sp. L049 collected from the sea grass Syringodium isoetifolium and was found to exhibit modest cytotoxicity against murine leukemia L1210 cells and human epidermoid carcinoma $\mathrm{KB}$ cells with $\mathrm{IC}_{50}$ values of 5 and $7 \mu \mathrm{g} / \mathrm{ml}$, respectively (Kasai et al., 2005). The carotenoid glycosyl ester, neurosporaxanthin $\beta$-D-glucopyranoside (198, Figure 13), was isolated from cultured cells of the marine microorganism, Fusarium sp., collected from the seawater surface and was the first naturally occurring neurosporaxanthin glycoside that was discovered (Sakaki et al., 2002).

\section{Other Classes}

Three polyketide glucosides containing a pyrone ringneofusapyrone (199), fusapyrone (200), and deoxyfusapyrone (201, Figure 14)-were obtained from the marine-derived fungus Fusarium sp. FH-146. All three compounds exhibited moderate active against Aspergillus clavatu with MIC values of $6.25,25$, and $3.12 \mu \mathrm{g} / \mathrm{ml}$, respectively (Hiramatsu et al., 2006). The fungus Aspergillus sydowii derived from the marine sponge, Stelletta sp., produced the $\beta$-D-glucopyranosyl, aspergillusene A (202, Figure 14), which was the first 


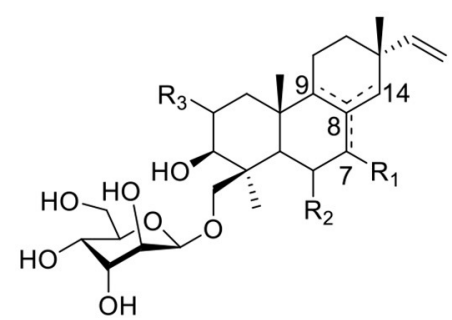

$174 \mathrm{R}_{1}=\mathrm{O}, \mathrm{R}_{2}=\mathrm{H}, \mathrm{R}_{3}=\alpha \mathrm{OH}, \Delta^{8,9}$

$175 \mathrm{R}_{1}=\mathrm{H}, \mathrm{R}_{2}=\beta \mathrm{OH}, \mathrm{R}_{3}=\mathrm{H}, \Delta^{7,8}$

$176 \mathrm{R}_{1}=\alpha \mathrm{OH}, \mathrm{R}_{2}=\mathrm{H}, \mathrm{R}_{3}=\mathrm{H}, \Delta^{8,14}$

$177 \mathrm{R}_{1}=\mathrm{O}, \mathrm{R}_{2}=\mathrm{H}, \mathrm{R}_{3}=\mathrm{H}, \Delta^{8,9}$

$178 R_{1}=H, R_{2}=H, R_{3}=H, \Delta^{7,8}$

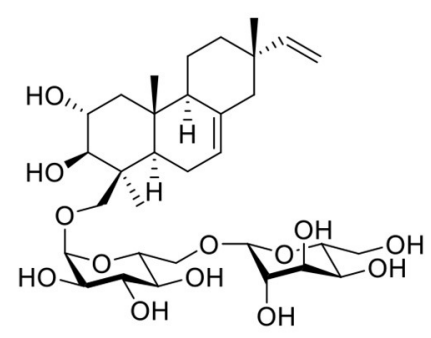

179

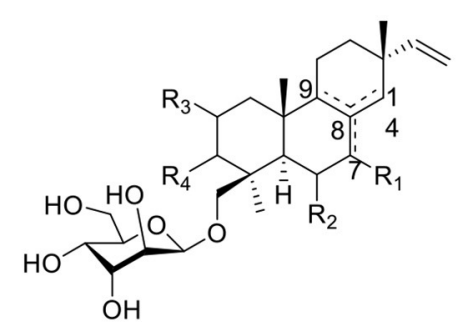

$180 \mathrm{R}_{1}=\alpha \mathrm{OH}, \mathrm{R}_{2}=\mathrm{H}, \mathrm{R}_{3}=\mathrm{H}, \mathrm{R}_{4}=\mathrm{O}$

$181 \mathrm{R}_{1}=\mathrm{O}, \mathrm{R}_{2}=\mathrm{H}, \mathrm{R}_{3}=\mathrm{H}, \mathrm{R}_{4}=\mathrm{O}, \Delta^{8,9}$

$182 \mathrm{R}_{1}=\mathrm{O}, \mathrm{R}_{2}=\mathrm{H}, \mathrm{R}_{3}=\mathrm{H}, \mathrm{R}_{4}=\mathrm{O}, \Delta^{8,14}$

$183 \mathrm{R}_{1}=\mathrm{O}, \mathrm{R}_{2}=\mathrm{H}, \mathrm{R}_{3}=\alpha \mathrm{OH}, \mathrm{R}_{4}=\beta \mathrm{OH}, \Delta^{8,14}$

$184 \mathrm{R}_{1}=\mathrm{H}, \mathrm{R}_{2}=\alpha \mathrm{OH}, \mathrm{R}_{3}=\alpha \mathrm{OH}, \mathrm{R}_{4}=\beta \mathrm{OH}, \Delta^{7,8}$

$185 \mathrm{R}_{1}=\alpha \mathrm{OH}, \mathrm{R}_{2}=\mathrm{H}, \mathrm{R}_{3}=\alpha \mathrm{OH}, \mathrm{R}_{4}=\beta \mathrm{OH}, \Delta^{8,9}$

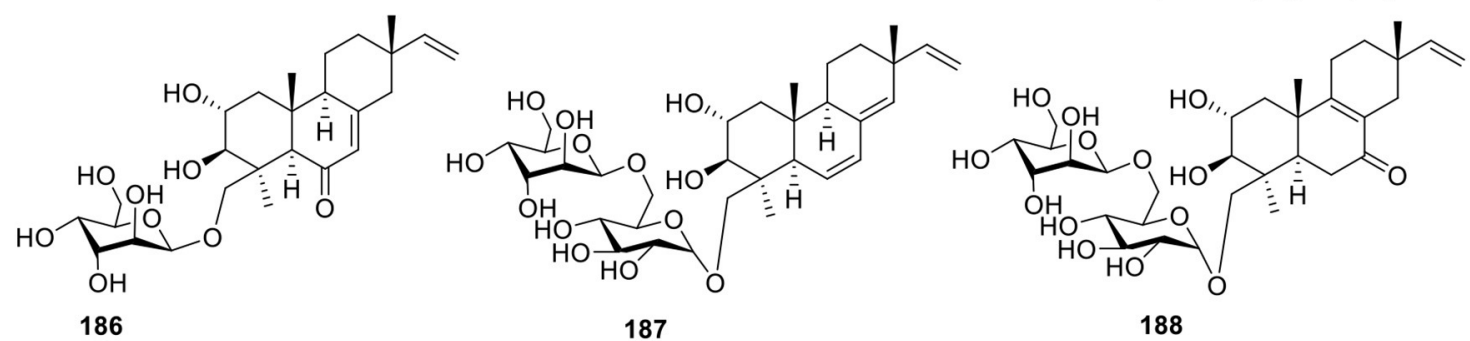

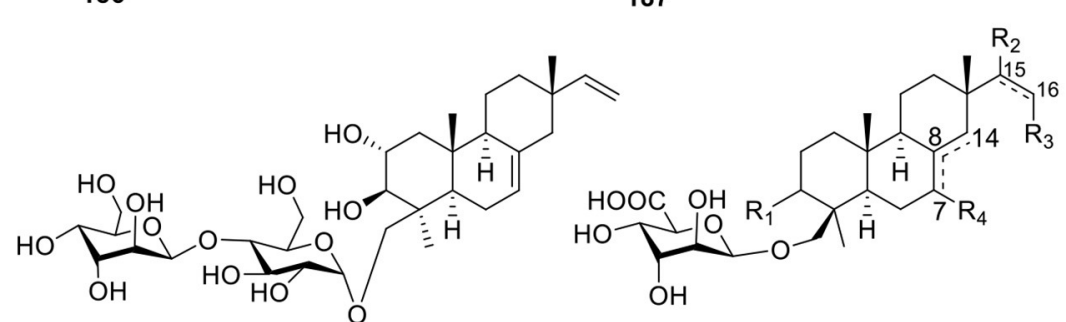

189

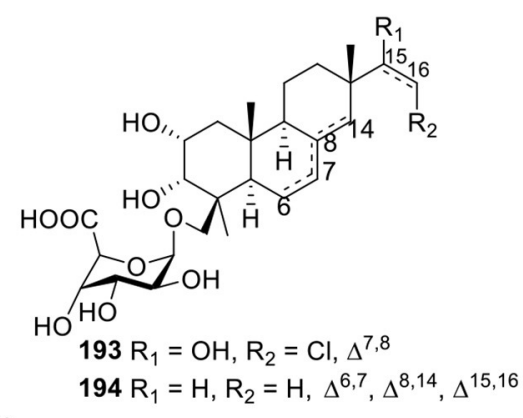

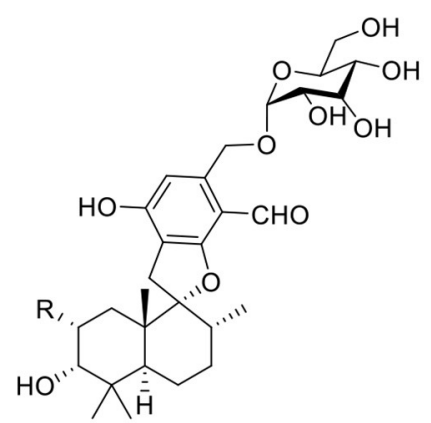

$195 \mathrm{R}=\mathrm{H}$

$196 \mathrm{R}=\mathrm{OH}$

$$
190 \mathrm{R}_{1}=\mathrm{O}, \mathrm{R}_{2}=\mathrm{H}, \mathrm{R}_{3}=\mathrm{H}, \mathrm{R}_{4}=\mathrm{H}, \Delta^{7,8}, \Delta^{15,16}
$$$$
191 \mathrm{R}_{1}=\mathrm{O}, \mathrm{R}_{2}=\mathrm{OH}, \mathrm{R}_{3}=\mathrm{Cl}, \mathrm{R}_{4}=\mathrm{H}, \Delta^{7,8}
$$

$193 \mathrm{R}_{1}=\mathrm{OH}, \mathrm{R}_{2}=\mathrm{Cl}, \Delta^{7,8}$$$
192 \mathrm{R}_{1}=\beta \mathrm{OH}, \mathrm{R}_{2}=\mathrm{H}, \mathrm{R}_{3}=\mathrm{H}, \mathrm{R}_{4}=\alpha \mathrm{OH}, \Delta^{8,14}, \Delta^{15,16}
$$<smiles>CCC(C)CC(C)CC(C)C(OC1C(O)C(O)C(O)C(O)C1O)C(C)C=C(C)C(O)C(C)C=C(C)C(O)C(C)C=C(C)C(O)C(C)C(=O)OC[C@H](O)[C@H](O)[C@H](O)CO</smiles><smiles>CC1=C(/C=C/C(C)=C/C=C/C(C)=C/C=C/C=C(C)/C=C/C=C(C)/C=C/C=C(\C)C(=O)OC2OC(CO)C(O)C2O)C(C)(C)CCC1</smiles>

198

FIGURE 13 | Chemical structures of compounds 174-198 derived from marine-sourced fungi.

glycoside of phenolic bisabolane sesquiterpenes that was discovered and exhibited mild antitumor activities against KB, HepG2 and HCT-116 cell lines (Liu et al., 2017). Three hydroquinone glycosides-acremonin A1-O- $\beta$-Dglucopyranoside (203), gliomastin E1-O- $\beta$-D-glucopyranoside (204), and 6'-O-acetyl-isohomoarbutin (205, Figure 14)were isolated from the marine-derived fungus, Gliomastix sp., originally derived from the hard coral, Stylophora sp. (Elnaggar et al., 2017).

\section{CONCLUSIONS}

According to an estimation, $\sim 70 \%$ of global drug leads derive directly from natural products, many of which are glycosylated 


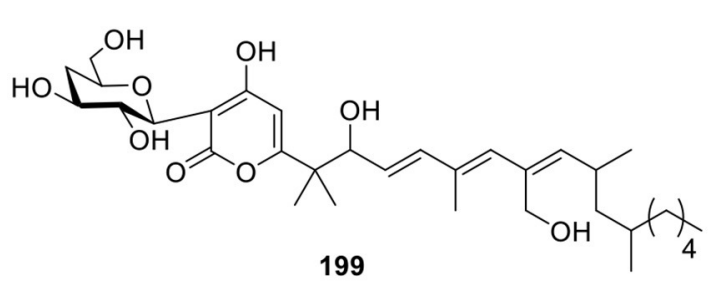

199<smiles>[R]CC(C=C(C)C=CC(O)C(C)(C)c1cc(=O)c(C2OC(O)C3(CO)COC2OC3O)c(O)o1)=CC(C)CC(C)(C)C</smiles>

$201 \mathrm{R}=\mathrm{H}$

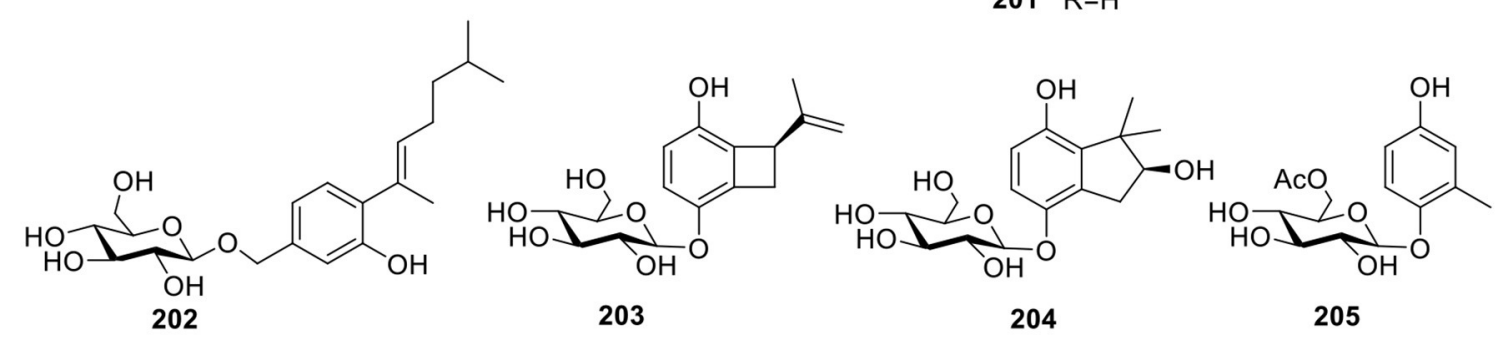

FIGURE 14 | Chemical structures of compounds 199-205 derived from marine-sourced fungi.

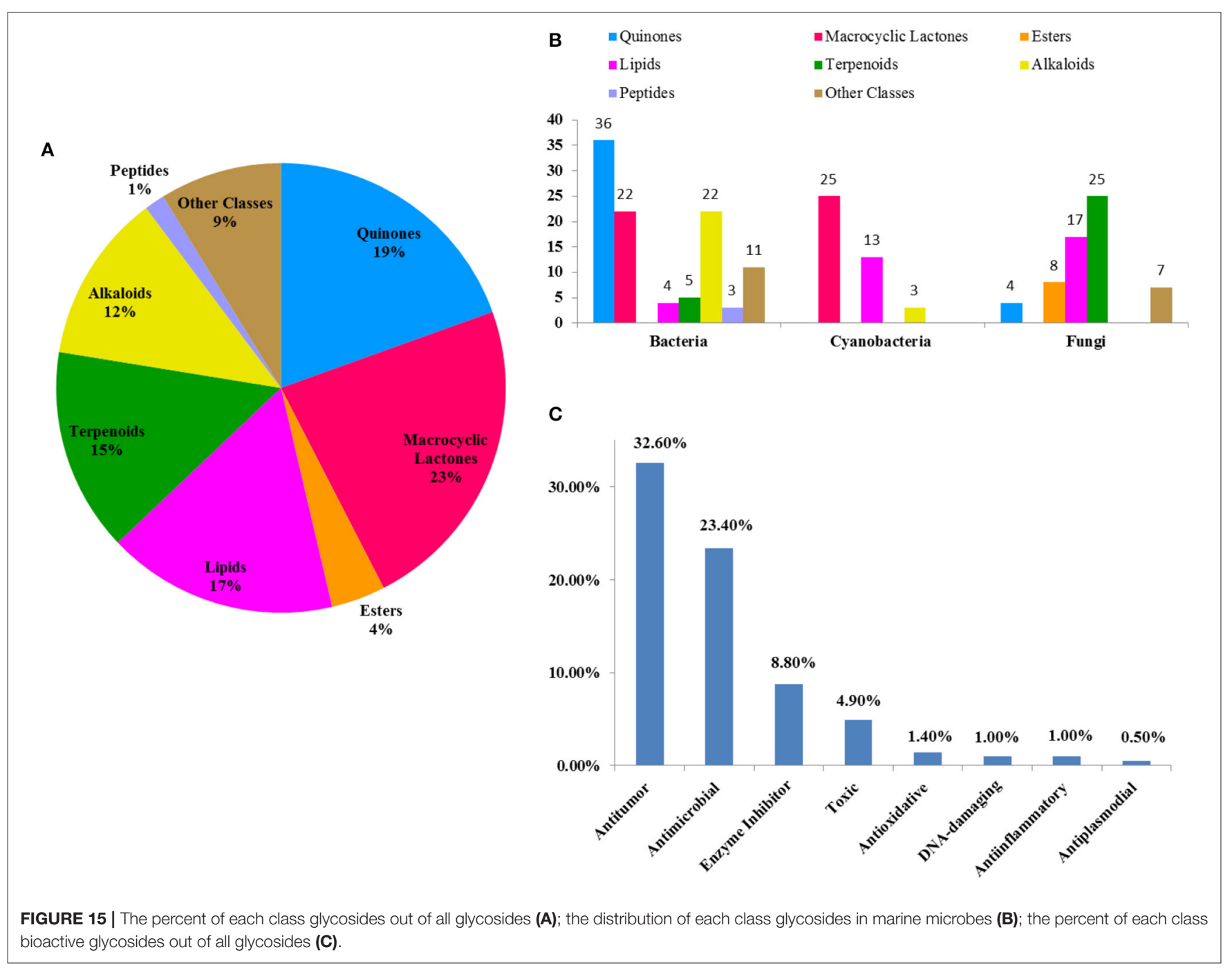


metabolites (Thorson et al., 2001). Chemical investigation for 205 glycosides of the last 22 years (1997-2018) suggests that these compounds are classified as quinones, macrocyclic lactones, esters, lipids, terpenoids, alkaloids, peptides, and other classes. Macrocyclic lactones and quinone glycosides comprise roughly $42 \%$ of all these compounds (Figure 15A), and bacteria were the main source of new glycosides at 50\% (104/205) (Figure 15B). Given the importance of glycoprotein to many biological processes, although peptide glycosides only account for $1 \%$ of these compounds, the peptide glycosides have a considerable potential for the discovery of drug leads.

In this review, the bioactivities of 129 glycosides were summarized in Tables S1-S3. In measured activities for these compounds, more than 50\% (Figure 15C) display antitumor and antimicrobial activities, some of which also possess strong cytotoxicity. For example, IB-00208 (16) had a strong antibiotic activity against Gram-positive organisms with MIC values ranging from 0.09 to $1.4 \mathrm{nM}$, and lomaiviticin A (34) had a unique cytotoxicity profile against cancer cell lines with $\mathrm{IC}_{50}$ values ranging from 0.01 to $98 \mathrm{ng} / \mathrm{ml}$. At present, two FDA-approved marine drugs, ara-C and ara-A, are antitumor and antiviral nucleosides, which are consistent with the main activity summarized in this review. This suggests that antitumor and antimicrobial drugs may be the main research direction for marine natural products. In addition, some glycosides also exhibited enzyme-inhibitory, antioxidative, DNA-damaging, anti-inflammatory, and anti-plasmodial activities. The recent indepth study of glycosides has revealed their dynamic potential as therapeutic agents in the treatment of different disorders. Based

\section{REFERENCES}

Adnani, N., Chevrette, M. G., Adibhatla, S. N., Zhang, F., Yu, Q., Braun, D. R., et al. (2017). Coculture of marine invertebrate-associated bacteria and interdisciplinary technologies enable biosynthesis and discovery of a new antibiotic, keyicin. ACS Chem. Biol. 12, 3093-3102. doi: $10.1021 /$ acschembio.7b00688

Afiyatullov, S., Kalinovsky, A. I., Pivkin, M. V., Dmitrenok, P. S., and Kuznetsova, T. A. (2006). New diterpene glycosides of the fungus Acremonium striatisporum isolated from a sea cucumber. Nat. Prod. Res. 20, 902-908. doi: $10.1080 / 14786410500277720$

Afiyatullov, S. S., Kalinovsky, A. I., and Antonov, A. S. (2011). New virescenosides from the marine-derived fungus Acremonium striatisporum. Nat. Prod. Commun. 6, 1063-1068. doi: 10.1177/1934578X1100600803

Afiyatullov, S. S., Kalinovsky, A. I., Antonov, A. S., Zhuravleva, O. I., Khudyakova, Y. V., Aminin, D. L., et al. (2016). Isolation and structures of virescenosides from the marine-derived fungus Acremonium striatisporum. Phytochem. Lett. 15, 66-71. doi: 10.1016/j.phytol.2015.11.010

Afiyatullov, S. S., Kalinovsky, A. I., Kuznetsova, T. A., Isakov, V. V., Pivkin, M. V., Dmitrenok, P. S., et al. (2002). New diterpene glycosides of the fungus Acremonium striatisporum isolated from a sea cucumber. J. Nat. Prod. 65, 641-644. doi: 10.1021/np010503y

Afiyatullov, S. S., Kalinovsky, A. I., Kuznetsova, T. A., Pivkin, M. V., Prokof'eva, N. G., Dmitrenok, P. S., et al. (2004). New glycosides of the fungus Acremonium striatisporum isolated from a sea cucumber. J. Nat. Prod. 67, 1047-1051. doi: $10.1021 / \mathrm{np} 0305324$

Afiyatullov, S. S., Kuznetsova, T. A., Isakov, V. V., Pivkin, M. V., Prokof'eva, N. G., and Elyakov, G. B. (2000). New diterpenic altrosides of the fungus Acremonium striatisporum isolated from a sea cucumber. J. Nat. Prod. 63, 848-850. doi: 10.1021/np9904004 on these findings, it may be possible to discover and develop glycosides with higher selectivities and efficacies.

\section{AUTHOR CONTRIBUTIONS}

$\mathrm{KL}$ and $\mathrm{XZ}$ designed and elaborated the manuscript. JC, $\mathrm{ZS}, \mathrm{BY}, \mathrm{XZ}$, and YL added valuable comments. XZ, JH, and HT critically revised and improved the manuscript. All authors read and approved the final version of the manuscript.

\section{FUNDING}

This research was supported by grants from the Guangdong MEPP Funds (GDME-2018C010, GDOE[2019]A28, 2019017), National Natural Science Foundation of China (81973235 and 21977102), Drug Innovation Major Project of China (2018ZX09735001-002-003), Guangzhou Science and Technology Project (201804010462), Guangdong Basic and Applied Basic Research Foundation (2018A0303130219 and 2019B151502042), and Project from Institution of South China Sea Ecology and Environmental Engineering, CAS (No. ISEE2018PY04).

\section{SUPPLEMENTARY MATERIAL}

The Supplementary Material for this article can be found online at: https://www.frontiersin.org/articles/10.3389/fchem. 2019.00879/full\#supplementary-material

Afonso, T. B., Costa, M. S., Rezende de Castro, R., Freitas, S., Silva, A., Schneider, M. P., et al. (2016). Bartolosides E-K from a marine coccoid cyanobacterium. J. Nat. Prod. 79, 2504-2513. doi: 10.1021/acs.jnatprod.6 b00351

Akhter, N., Liu, Y., Auckloo, B. N., Shi, Y., Wang, K., Chen, J., et al. (2018). Stress-driven discovery of new angucycline-type antibiotics from a marine Streptomyces pratensis NA-ZhouS1. Mar. Drugs. 16:E331. doi: $10.3390 / \mathrm{md} 16090331$

Andrianasolo, E. H., Gross, H., Goeger, D., Musafija-Girt, M., McPhail, K. P., Leal, R. M., et al. (2005). Isolation of swinholide A and related glycosylated derivatives from two field collections of marine cyanobacteria. Org. Lett. 7, 1375-1378. doi: 10.1021/ol050188x

Asolkar, R. N., Kirkland, T. N., Jensen, P. R., and Fenical, W. (2010). Arenimycin, an antibiotic effective against rifampin- and methicillin-resistant Staphylococcus aureus from the marine actinomycete Salinispora arenicola. J. Antibiot. 63, 37-39. doi: 10.1038/ja.2009.114

Asolkar, R. N., Maskey, R. P., Helmke, E., and Laatsch, H. (2002). Chalcomycin B, a new macrolide antibiotic from the marine isolate Streptomyces sp B7064. J. Antibiot. 55, 893-898. doi: 10.7164/antibiotics.55.893

Bae, M., Moon, K., Kim, J., Park, H. J., Lee, S. K., Shin, J., et al. (2016). Mohangic acids A-E, p-aminoacetophenonic acids from a marine-mudflatderived Streptomyces sp. J. Nat. Prod. 79, 332-339. doi: 10.1021/acs.jnatprod.5b 00956

Blanchard, S., and Thorson, J. S. (2006). Enzymatic tools for engineering natural product glycosylation. Curr. Opin. Chem. Biol. 10, 263-271. doi: 10.1016/j.cbpa.2006.04.001

Bringmann, G., Lang, G., Steffens, S., Günther, E., and Schaumann, K. (2003). Evariquinone, isoemericellin, and stromemycin from a sponge derived strain of the fungus Emericella variecolor. Phytochemistry 63, 437-443. doi: 10.1016/s0031-9422(03)00189-4 
Che, Q., Qiao, L., Han, X., Liu, Y., Wang, W., Gu, Q., et al. (2018). Anthranosides A-C, anthranilate derivatives from a sponge-derived Streptomyces sp. CMN-62. Org Lett. 20, 5466-5469. doi: 10.1021/acs.orglett.8b02382

Chen, S., Zhang, D., Chen, M., Zhang, Z., and Lian, X. Y. (2018). A rare diketopiperazine glycoside from marine-sourced Streptomyces sp. ZZ446. Nat. Prod. Res. 1-5. doi: 10.1080/14786419.2018.1544978

Chen, Z., Zheng, Z., Huang, H., Song, Y., Zhang, X., Ma, J., et al. (2012). Penicacids A-C, three new mycophenolic acid derivatives and immunosuppressive activities from the marine-derived fungus Penicillium sp. SOF07. Bioorg. Med. Chem. Lett. 22, 3332-3335. doi: 10.1016/j.bmcl.2012.02.106

Chinworrungsee, M., Kittakoop, P., Isaka, M., Chanphen, R., Tanticharoen, M., and Thebtaranonth, Y. (2002). Halorosellins A and B, unique isocoumarin glucosides from the marine fungus Halorosellinia oceanica. J. Chem. Soc. Perkin Trans. 1.2473-2476. doi: 10.1039/b207887m

Cui, J., Morita, M., Ohno, O., Kimura, T., Teruya, T., Watanabe, T., et al. (2017). Leptolyngbyolides, cytotoxic macrolides from the marine cyanobacterium Leptolyngbya sp.: isolation, biological activity, and catalytic asymmetric total synthesis. Chemistry 23, 8500-8509. doi: 10.1002/chem.2017 01183

Ding, H., Zhang, D., Zhou, B., and Ma, Z. (2017). Inhibitors of BRD4 protein from a marine-derived fungus Alternaria sp. NH-F6. Mar. Drugs. 15:E76. doi: $10.3390 / \mathrm{md} 15030076$

Dyshlovoy, S. A., and Honecker, F. (2018). Marine compounds and cancer: 2017 updates. Mar. Drugs. 16:E41. doi: 10.3390/md16020041

Elnaggar, M. S., Ebrahim, W., Mándi, A., Kurtán, T., Müller, W. E. G., Kalscheuer, R., et al. (2017). Hydroquinone derivatives from the marine-derived fungus Gliomastix sp. RSC Adv. 7, 30640-30649. doi: 10.1039/C7RA04941B

Ford, P. W., Gadepelli, M., and Davidson, B. S. (1998). Halawanones A-D, new polycyclic quinones from a marine-derived streptomycete. J. Nat. Prod. 61, 1232-1236. doi: 10.1021/np980126y

Fu, P., Liu, P., Li, X., Wang, Y., Wang, S., Hong, K., et al. (2011). Cyclic Bipyridine glycosides from the marine-derived actinomycete Actinoalloteichus cyanogriseus WH1-2216-6. Org. Lett. 13, 5948-5951. doi: 10.1021/ol202245s

Gantt, R. W., Peltier-Pain, P., and Thorson, J. S. (2011). Enzymatic methods for glyco(diversification/randomization) of drugs and small molecules. Nat. Prod. Rep. 28, 1811-1853. doi: 10.1039/clnp00045d

Grynkiewicz, G., Szeja, W., and Boryski, J. (2008). Synthetic analogs of natural glycosides in drug discovery and development. Acta Pol. Pharm. 65, 655-676.

Gui, C., Zhang, S., Zhu, X., Ding, W., Huang, H., Gu, Y. C., et al. (2017). Antimicrobial spirotetronate metabolites from marine-derived Micromonospora harpali SCSIO GJ089. J. Nat. Prod. 80, 1594-1603. doi: 10.1021/acs.jnatprod.7b00176

Gunasekera, S. P., Li, Y., Ratnayake, R., Luo, D., Lo, J., Reibenspies, J. H., et al. (2016). Discovery, total synthesis and key structural elements for the immunosuppressive activity of cocosolide, a symmetrical glycosylated macrolide dimer from marine cyanobacteria. Chemistry 22, 8158-8166. doi: $10.1002 /$ chem. 201600674

Guo, Z. K., Wang, R., Liu, T. M., Chen, F. X., and Yang, M. Q. (2019). A new flavonoid derivative and a new 5-hydroxyanthranilic acid derivative from the sea urchin-derived Streptomyces sp. HDa1. J. Asian Nat. Prod. Res. 21, 992-998. doi: $10.1080 / 10286020.2018 .1485663$

He, H. Y., Ding, W. D., Bernan, V. S., Richardson, A. D., Ireland, C. M., Greenstein, M., et al. (2001). Lomaiviticins A and B, potent antitumor antibiotics from Micromonospora lomaivitiensis. J. Am. Chem. Soc. 123, 5362-5363. doi: $10.1021 / \mathrm{ja} 010129 \mathrm{o}$

Hiramatsu, F., Miyajima, T., Murayama, T., Takahashi, K., Koseki, T., and Shiono, Y. (2006). Isolation and structure elucidation of neofusapyrone from a marine-derived Fusarium species, and structural revision of fusapyrone and deoxyfusapyrone. J. Antibiot. 59, 704-709. doi: 10.1038/ja.2006.94

Huang, H., Yao, Y., He, Z., Yang, T., Ma, J., Tian, X., et al. (2011). Antimalarial betacarboline and indolactam alkaloids from Marinactinospora thermotolerans, a deep sea isolate. J. Nat. Prod. 74, 2122-2127. doi: 10.1021/np200399t

Huang, Z., Yang, J., Lei, F., She, Z., and Lin, Y. (2013). A new xanthone O-glycoside from the mangrove endophytic fungus Phomopsis sp. Chem. Natur. Comp. 49, 27-30. doi: 10.1007/s10600-013-0497-0

Itoh, T., Kinoshita, M., Aoki, S., and Kobayashi, M. (2003). Komodoquinone A, a neuritogenic anthracycline, from marine Streptomyces sp KS3. J. Nat. Prod. 66, 1373-1377. doi: 10.1021/np030212k
Jiang, S., Zhang, L., Pei, X., Deng, F., Hu, D., Chen, G., et al. (2017). Chalcomycins from marine-derived Streptomyces sp. and their antimicrobial activities. Mar. Drugs. 15:E153. doi: 10.3390/md15060153

Jiang, T., Li, T., Li, J., Fu, H. Z., Pei, Y. H., and Lin, W. H. (2004). Cerebroside analogues from marine-derived fungus Aspergillus flavipes. J. Asian Nat. Prod. Res. 6, 249-257. doi: 10.1080/1028602031000147384

Jiang, X., Zhang, Q., Zhu, Y., Nie, F., Wu, Z., Yang, C., et al. (2017). Isolation, structure elucidation and biosynthesis of benzo[ $b$ ]fluorene nenestatin A from deep-sea derived Micromonospora echinospora SCSIO 04089. Tetrahedron 73, 3585-3590. doi: 10.1016/j.tet.2017.03.054

Jiang, Z.-D., Jensen, P. R., and Fenical, W. (1997). Actinoflavoside, a flavonoidlike glycoside produced by a marine bacterium of the genus Streptomyces. Tetrahedron Lett. 38, 5065-5068. doi: 10.1016/S0040-4039(97)01127-1

Jiang, Z. D., Jensen, P. R., and Fenical, W. (1999). Lobophorins A and B, new antiinflammatory macrolides produced by a tropical marine bacterium. Bioorg. Med. Chem. Lett. 9, 2003-2006. doi: 10.1016/s0960-894x(99)00337-6

Jimenez, C. (2018). Marine natural products in medicinal chemistry. ACS Med. Chem. Lett. 9, 959-961. doi: 10.1021/acsmedchemlett.8b00368

Kalinovskaya, N. I., Kalinovsky, A. I., Romanenko, L. A., Dmitrenok, P. S., and Kuznetsova, T. A. (2010). New angucyclines and antimicrobial diketopiperazines from the marine mollusk-derived actinomycete Saccharothrix espanaensis An 113. Nat. Prod. Commun. 5, 597-602. doi: $10.1177 / 1934578 X 1000500420$

Kalinovskaya, N. I., Kalinovsky, A. I., Romanenko, L. A., Pushilin, M. A., Dmitrenok, P. S., and Kuznetsova, T. A. (2008). New angucyclinones from the marine mollusk associated actinomycete Saccharothrix espanaensis An 113. Nat. Prod. Commun. 3, 1611-1616. doi: 10.1177/1934578X0800301006

Kalinovskaya, N. I., Romanenko, L. A., Kalinovsky, A. I., Ermakova, S. P., Dmitrenok, P. S., and Afiyatullov, S. S. (2017). The antitumor antibiotics complex of aureolic acids from the marine sediment-associated strain of Streptomyces sp KMM 9048. Nat. Prod. Commun. 12, 571-577. doi: 10.1177/1934578X1701200427

Kasai, Y., Komatsu, K., Shigemori, H., Tsuda, M., Mikami, Y., and Kobayashi, J. (2005). Cladionol A, a polyketide glycoside from marine-derived fungus Gliocladium species. J. Nat. Prod. 68, 777-779. doi: 10.1021/np050046b

Klein, D., Braekman, J. C., Daloze, D., Hoffmann, L., and Demoulin, V. (1997). Lyngbyaloside, a 2,3,4-tri-O-methyl-6-deoxy-alpha-mannopyranoside macrolide from Lyngbya bouillonii (Cyanobacteria). J. Nat. Prod. 60, 1057-1059. doi: 10.1021/np9702751

Kong, X., Ma, X., Xie, Y., Cai, S., Zhu, T., Gu, Q., et al. (2013). Aromatic polyketides from a sponge-derived fungus Metarhizium anisopliae mxh99 and their antitubercular activities. Arch. Pharm. Res. 36, 739-744. doi: 10.1007/s12272-013-0077-7

Lai, Z., Yu, J., Ling, H., Song, Y., Yuan, J., Ju, J., et al. (2018). Grincamycins I - K, cytotoxic angucycline glycosides derived from marine-derived actinomycete Streptomyces lusitanus SCSIO LR32. Planta Med. 84, 201-207. doi: $10.1055 / \mathrm{s}-0043-119888$

Leão, P. N., Nakamura, H., Costa, M., Pereira, A. R., Martins, R., Vasconcelos, V., et al. (2015). Biosynthesis-assisted structural elucidation of the bartolosides, chlorinated aromatic glycolipids from cyanobacteria. Angew. Chem. Int. Ed Engl. 54, 11063-11067. doi: 10.1002/anie.201503186

Leet, J. E., Li, W. Y., Ax, H. A., Matson, J. A., Huang, S., Huang, R., et al. (2003). Nocathiacins, new thiazolyl peptide antibiotics from Nocardia sp. II. Isolation, characterization, and structure determination. J. Antibiot. 56, 232-242. doi: 10.7164/antibiotics.56.232

Li, K., Li, Q. L., Ji, N. Y., Liu, B., Zhang, W., and Cao, X. P. (2011). Deoxyuridines from the marine sponge associated actinomycete Streptomyces microflavus. Mar. Drugs. 9, 690-695. doi: 10.3390/md9050690

Li, S., Tian, X., Niu, S., Zhang, W., Chen, Y., Zhang, H., et al. (2011). Pseudonocardians A-C, new diazaanthraquinone derivatives from a deap-sea actinomycete Pseudonocardia sp. SCSIO 01299. Mar. Drugs. 9, 1428-1439. doi: 10.3390/md9081428

Li, W. Y., Leet, J. E., Ax, H. A., Gustavson, D. R., Brown, D. M., Turner, L., et al. (2003). Nocathiacins, new thiazolyl peptide antibiotics from Nocardia sp I. Taxonomy, fermentation and biological activities. J. Antibiot. 56, 226-231. doi: 10.7164/antibiotics.56.226

Li, Y., Li, X., Lee, U., Kang, J. S., Choi, H. D., and Son, B. W. (2006). A new radical scavenging anthracene glycoside, asperflavin ribofuranoside, and polyketides 
from a marine isolate of the fungus Microsporum. Chem. Pharm. Bull. 54, 882-883. doi: $10.1248 / \mathrm{cpb} .54 .882$

Lin, Z., Flores, M., Forteza, I., Henriksen, N. M., Concepcion, G. P., Rosenberg, G., et al. (2012). Totopotensamides, polyketide-cyclic peptide hybrids from a mollusk-associated bacterium Streptomyces sp. J. Nat. Prod. 75, 644-649. doi: $10.1021 / \mathrm{np} 200886 \mathrm{x}$

Liu, S., Wang, H., Su, M., Hwang, G. J., Hong, J., and Jung, J. H. (2017). New metabolites from the sponge-derived fungus Aspergillus sydowii J05B-7F-4. Nat. Prod. Res. 31, 1682-1686. doi: 10.1080/14786419.2017.1289205

Luesch, H., Yoshida, W. Y., Harrigan, G. G., Doom, J. P., Moore, R. E., and Paul, V. J. (2002). Lyngbyaloside B, a new glycoside macrolide from a Palauan marine cyanobacterium, Lyngbya sp. J. Nat. Prod. 65, 1945-1948. doi: 10.1021/np0202879

Ma, X., Li, L., Zhu, T., Ba, M., Li, G., Gu, Q., et al. (2013). Phenylspirodrimanes with anti-HIV activity from the sponge-derived fungus Stachybotrys chartarum MXH-X73. J. Nat. Prod. 76, 2298-2306. doi: 10.1021/np400683h

Malet-Cascon, L., Romero, F., Espliego-Vazquez, F., Gravalos, D., and FernandezPuentes, J. L. (2003). IB-00208, a new cytotoxic polycyclic xanthone produced by a marine-derived Actinomadura I. Isolation of the strain, taxonomy and biological activites. J. Antibiot. 56, 219-225. doi: 10.7164/antibiotics.56.219

Maskey, R. P., Helmke, E., Fiebig, H. H., and Laatsch, H. (2002). Parimycin: Isolation and structure elucidation of a cytotoxic 2,3-dihydroquinizarin analogue of gamma-indomycinone from a marine streptomycete isolate. $J$. Antibiot. 55, 1031-1035. doi: 10.7164/antibiotics.55.1031

Maskey, R. P., Helmke, E., Kayser, O., Fiebig, H. H., Maier, A., Busche, A., et al. (2004a). Anti-cancer and antibacterial trioxacarcins with high anti-malaria activity from - a marine Streptomycete and their absolute stereochemistry. J. Antibiot. 57, 771-779. doi: 10.7164/antibiotics.57.771

Maskey, R. P., Sevvana, M., Uson, I., Helmke, E., and Laatsch, H. (2004b). Gutingimycin: a highly complex metabolite from a marine streptomycete. Angew. Chem. Int. Ed Engl. 43, 1281-1283. doi: 10.1002/anie.200352312

Matthew, S., Salvador, L. A., Schupp, P. J., Paul, V. J., and Luesch, H. (2010). Cytotoxic halogenated macrolides and modified peptides from the apratoxinproducing marine cyanobacterium Lyngbya bouillonii from guam. J. Nat. Prod. 73, 1544-1552. doi: 10.1021/np1004032

Mondol, M. A., Kim, J. H., Lee, H. S., Lee, Y. J., and Shin, H. J. (2011). Macrolactin W, a new antibacterial macrolide from a marine Bacillus sp. Bioorg. Med. Chem. Lett. 21, 3832-3835. doi: 10.1016/j.bmcl.2010.12.050

Morita, M., Ohno, O., Teruya, T., Yamori, T., Inuzuka, T., and Suenaga, K. (2012). Isolation and structures of biselyngbyasides $\mathrm{B}, \mathrm{C}$, and $\mathrm{D}$ from the marine cyanobacterium Lyngbya sp., and the biological activities of biselyngbyasides. Tetrahedron 68, 5984-5990. doi: 10.1016/j.tet.2012.05.038

Motohashi, K., Takagi, M., and Shin-ya, K. (2010). Tetracenoquinocin and 5iminoaranciamycin from a sponge-derived Streptomyces sp. Sp080513GE-26. J. Natur. Products. 73, 755-758. doi: 10.1021/np9007409

Murshid, S. S. A., Badr, J. M., and Youssef, D. T. A. (2016). Penicillosides A and B: new cerebrosides from the marine-derived fungus Penicillium species. Revista Brasileira de Farmacognosia. 26, 29-33. doi: 10.1016/j.bjp.2015.09.007

Navarro, G., Cummings, S., Lee, J., Moss, N., Glukhov, E., Valeriote, F. A., et al. (2015). Isolation of polycavernoside D from a marine cyanobacterium. Environ. Sci. Technol. Lett. 2, 166-170. doi: 10.1021/acs.estlett.5b00116

Nogle, L. M., and Gerwick, W. H. (2003). Diverse secondary metabolites from a Puerto Rican collection of Lyngbya majuscula. J. Nat. Prod. 66, 217-220. doi: $10.1021 / \mathrm{np} 020332 \mathrm{c}$

Oh, D. C., Williams, P. G., Kauffman, C. A., Jensen, P. R., and Fenical, W. (2006). Cyanosporasides A and B, chloro- and cyano-cyclopenta a indene glycosides from the marine actinomycete "Salinispora pacifica". Org. Lett. 8, 1021-1024. doi: $10.1021 / 01052686 \mathrm{~b}$

Omura, S., Tomoda, H., Tabata, N., Ohyama, Y., Abe, T., and Namikoshi, M. (1999). Roselipins, fungal metabolites having a highly methylated fatty acid modified with a mannose and an arabinitol. J. Antibiot. 52, 586-589. doi: 10.7164/antibiotics.52.586

Phipps, R. K., Blunt, J. W., Cole, A. L. J., and Munro, M. H. G. (2004). Anthracycline derivatives from a marine-derived New Zealand Streptomycete. ARKIVOC 2004:94-100. doi: 10.3998/ark.5550190.0005.a10

Qi, J., Shao, C. L., Li, Z. Y., Gan, L. S., Fu, X. M., Bian, W. T., et al. (2013). Isocoumarin derivatives and benzofurans from a sponge-derived Penicillium sp. fungus. J. Nat. Prod. 76, 571-579. doi: 10.1021/np3007556
Qin, L.-L., Zhou, B., Ding, W., and Ma, Z. (2018). Bioactive metabolites from marine-derived Streptomyces sp. A68 and its Rifampicin resistant mutant strain R-M1. Phytochem. Lett. 23, 46-51. doi: 10.1016/j.phytol.2017.11.002

Rodriguez, J. C., Puentes, J. L. F., Baz, J. P., and Canedo, L. M. (2003). IB-00208, a new cytotoxic polycyclic xanthone produced by a marinederived Actinomadura II. Iolation, physico-chemical properties and structure determination. J. Antibiot. 56, 318-321. doi: 10.7164/antibiotics.56.318

Rukachaisirikul, V., Rodglin, A., Sukpondma, Y., Phongpaichit, S., Buatong, J., and Sakayaroj, J. (2012). Phthalide and isocoumarin derivatives produced by an Acremonium sp. isolated from a mangrove Rhizophora apiculata. J. Nat. Prod. 75, 853-858. doi: 10.1021/np20 $0885 \mathrm{e}$

Sakaki, H., Kaneno, H., Sumiya, Y., Tsushima, M., Miki, W., Kishimoto, N., et al. (2002). A new carotenoid glycosyl ester isolated from a marine microorganism, Fusarium strain T-1. J. Nat. Prod. 65, 1683-1684. doi: 10.1021/np010554v

Sarmiento-Vizcaino, A., Brana, A. F., Perez-Victoria, I., Martin, J., de Pedro, N., Cruz, M., et al. (2017). Paulomycin G, a new natural product with cytotoxic activity against tumor cell lines produced by deep-sea sediment derived micromonospora matsumotoense M-412 from the aviles canyon in the Cantabrian Sea. Mar. Drugs. 15:E271. doi: 10.3390/md15090271

Schleissner, C., Perez, M., Losada, A., Rodriguez, P., Crespo, C., Zuniga, P., et al. (2011). Antitumor actinopyranones produced by Streptomyces albus POR04-15-053 isolated from a marine sediment. J. Nat. Prod. 74, 1590-1596. doi: 10.1021/np200196j

Schneemann, I., Kajahn, I., Ohlendorf, B., Zinecker, H., Erhard, A., Nagel, K., et al. (2010). Mayamycin, a cytotoxic polyketide from a Streptomyces strain isolated from the marine sponge Halichondria panicea. J. Nat. Prod. 73, 1309-1312. doi: 10.1021/np100135b

Schumacher, R. W., Harrigan, B. L., and Davidson, B. S. (2001). Kahakamides A and $\mathrm{B}$, new neosidomycin metabolites from a marine-derived actinomycete. Tetrahedron Lett. 42, 5133-5135. doi: 10.1016/S0040-4039(01)00979-0

Seo, C., Sohn, J. H., Oh, H., Kim, B. Y., and Ahn, J. S. (2009). Isolation of the protein tyrosine phosphatase $1 \mathrm{~B}$ inhibitory metabolite from the marine-derived fungus Cosmospora sp. SF-5060. Bioorg. Med. Chem. Lett. 19, 6095-6097. doi: 10.1016/j.bmcl.2009.09.025

Shaaban, K. A., Helmke, E., Kelter, G., Fiebig, H. H., and Laatsch, H. (2011). Glucopiericidin C: a cytotoxic piericidin glucoside antibiotic produced by a marine Streptomyces isolate. J. Antibiot. 64, 205-209. doi: 10.1038/ja.2010.125

Shindo, K., Asagi, E., Sano, A., Hotta, E., Minemura, N., Mikami, K., et al. (2008a). Diapolycopenedioic acid xylosyl esters A, B, and C, antioxidative glyco-C(30)-carotenoic acids produced by a new marine bacterium Rubritalea squalenifaciens. J. Antibiot. 61, 185-191. doi: 10.1038/ja.2008.28

Shindo, K., Endo, M., Miyake, Y., Wakasugi, K., Morritt, D., Bramley, P. M., et al. (2008b). Methyl glucosyl-3,4-dehydro-apo-8 '-lycopenoate, a antioxidative glyco-C-30-carotenoic acid produced by a marine bacterium Planococcus maritimus. J. Antibiot. 61, 729-735. doi: 10.1038/ja.2008.86

Shindo, K., Mikami, K., Tamesada, E., Takaichi, S., Adachi, K., Misawa, N., et al. (2007). Diapolycopenedioic acid xylosyl ester, a glyco-C30carotenoic acid produced by a new marine bacterium Rubritalea squalenifaciens. Tetrahedron Lett. 48, 2725-2727. doi: 10.1016/j.tetlet.2007. 02.065

Tabata, N., Ohyama, Y., Tomoda, H., Abe, T., Namikoshi, M., and Omura, S. (1999). Structure elucidation of roselipins, inhibitors of diacylglycerol acyltransferase produced by Gliocladium roseum KF-1040. J. Antibiot. 52, 815-826. doi: 10.7164/antibiotics.52.815

Tan, L. T., Marquez, B. L., and Gerwick, W. H. (2002). Lyngbouilloside, a glycosidic macrolide from the marine cyanobacterium Lyngbya bouillonii. J. Nat. Prod. 65, 925-928. doi: $10.1021 / \mathrm{np} 010526 \mathrm{c}$

Tao, Y., Li, P., Zhang, D., Glukhov, E., Gerwick, L., Zhang, C., et al. (2018). Samholides, swinholide-related metabolites from a marine cyanobacterium cf. Phormidium sp. J. Org. Chem. 83, 3034-3046. doi: 10.1021/acs.joc.8b00028

Tareq, F. S., Kim, J. H., Lee, M. A., Lee, H.-S., Lee, Y.-J., Lee, J. S., et al. (2012). Ieodoglucomides A and B from a marine-derived bacterium Bacillus licheniformis. Org. Lett. 14, 1464-1467. doi: 10.1021/ol300202z

Tedesco, P., Maida, I., Palma Esposito, F., Tortorella, E., Subko, K., Ezeofor, C. C., et al. (2016). Antimicrobial activity of monoramnholipids produced by bacterial strains isolated from the Ross Sea (Antarctica). Mar. Drugs. 14:E83. doi: $10.3390 / \mathrm{md} 14050083$ 
Teruya, T., Sasaki, H., Kitamura, K., Nakayama, T., and Suenaga, K. (2009). Biselyngbyaside, a macrolide glycoside from the marine cyanobacterium Lyngbya sp. Org. Lett. 11, 2421-2424. doi: 10.1021/ol900579k

Thorson, J. S., Hosted, J., Jiang, J., Biggins, J. B., and Ahlert, J. (2001). Natures carbohydrate chemists the enzymatic glycosylation of bioactive bacterial metabolites. Curr. Org. Chem. 5, 139-167. doi: 10.2174/1385272013375706

Wang, C. X., Ding, R., Jiang, S. T., Tang, J. S., Hu, D., Chen, G. D., et al. (2016). Aldgamycins J-O, 16-membered macrolides with a branched octose unit from Streptomycetes sp. and their antibacterial activities. J. Nat. Prod. 79, 2446-2454. doi: 10.1021/acs.jnatprod.6b00200

Wang, J. N., Zhang, H. J., Li, J. Q., Ding, W. J., and Ma, Z. J. (2018). Bioactive Indolocarbazoles from the marine-derived Streptomyces sp. DT-A61. J. Nat. Prod. 81, 949-956. doi: 10.1021/acs.jnatprod.7b01058

Wang, L., Wang, J., Liu, J., and Liu, Y. (2018). Antitubercular marine natural products. Curr. Med. Chem. 25, 2304-2328. doi: $10.2174 / 0929867324666170113120221$

Wang, W., Wang, Y., Tao, H., Peng, X., Liu, P., and Zhu, W. (2009). Cerebrosides of the halotolerant fungus Alternaria raphani isolated from a sea salt field. J. Nat. Prod. 72, 1695-1698. doi: 10.1021/np9002299

Wei, R. B., Xi, T., Li, J., Wang, P., Li, F. C., Lin, Y. C., et al. (2011). Lobophorin $\mathrm{C}$ and $\mathrm{D}$, new kijanimicin derivatives from a marine sponge-associated actinomycetal strain AZS17. Mar. Drugs. 9, 359-368. doi: 10.3390/md9030359

Wu, M., Milligan, K. E., and Gerwick, W. H. (1997). Three new malyngamides from the marine cyanobacterium Lyngbya majuscula. Tetrahedron 53, 15983-15990. doi: 10.1016/S0040-4020(97)10067-9

Wu, Z.-J., Ouyang, M.-A., Su, R.-K., and Kuo, Y.-H. (2008). Two new cerebrosides and anthraquinone derivatives from the marine funguis Aspergillus niger. Chinese J. Chem. 26, 759-764. doi: 10.1002/cjoc.200890142

Yamada, T., Minoura, K., and Numata, A. (2002). Halichoblelide, a potent cytotoxic macrolide from a Streptomyces species separated from a marine fish. Tetrahedron Lett. 43, 1721-1724. doi: 10.1016/S0040-4039(02)00102-8

Yang, G., Sandjo, L., Yun, K., Leutou, A. S., Kim, G.-D., Choi, H. D., et al. (2011). Flavusides A and B, antibacterial cerebrosides from the marine-derived fungus Aspergillus flavus. Chem. Pharm. Bull. 59, 1174-1177. doi: 10.1248/cpb.59.1174

Ye, X., Anjum, K., Song, T., Wang, W., Yu, S., Huang, H., et al. (2016). A new curvularin glycoside and its cytotoxic and antibacterial analogues from marine actinomycete Pseudonocardia sp. HS7. Nat. Prod. Res. 30, 1156-1161. doi: 10.1080/14786419.2015.1047775

Youssef, D. T., Ibrahim, S. R., Shaala, L. A., Mohamed, G. A., and Banjar, Z. M. (2016). New cerebroside and nucleoside derivatives from a Red Sea strain of the marine cyanobacterium moorea producens. Molecules 21:324. doi: 10.3390/molecules21030324

Yu, B., Sun, J., and Yang, X. (2012). Assembly of naturally occurring glycosides, evolved tactics, and glycosylation methods. Acc. Chem. Res. 45, 1227-1236. doi: 10.1021/ar200296m

Zeng, Y. B., Wang, H., Zuo, W. J., Zheng, B., Yang, T., Dai, H. F., et al. (2012). A fatty acid glycoside from a marine-derived fungus isolated from mangrove plant Scyphiphora hydrophyllacea. Mar. Drugs. 10, 598-603. doi: $10.3390 / \mathrm{md} 10030598$

Zhang, L.-H., Li, S.-G., Wu, H.-H., Chen, G., Li, L., Bai, J., et al. (2017). 3,4-Dihydroisocoumarin derivatives from the marine-derived fungus Paraconiothyrium sporulosum YK-03. Phytochem. Lett. 20, 200-203. doi: 10.1016/j.phytol.2017.04.039

Zhang, S., Gui, C., Shao, M., Kumar, P. S., Huang, H., and Ju, J. (2018). Antimicrobial tunicamycin derivatives from the deep seaderived Streptomyces xinghaiensis SCSIO S15077. Nat. Prod. Res. 1-6. doi: 10.1080/14786419.2018.1493736

Zhou, B., Qin, L.-L., Ding, W.-J., and Ma, Z.-J. (2018). Cytotoxic indolocarbazoles alkaloids from the Streptomyces sp. A65. Tetrahedron 74, 726-730. doi: 10.1016/j.tet.2017.12.048

Conflict of Interest: The authors declare that the research was conducted in the absence of any commercial or financial relationships that could be construed as a potential conflict of interest.

Copyright (c) $2020 \mathrm{Li}$, Cai, Su, Yang, Liu, Zhou, Huang and Tao. This is an openaccess article distributed under the terms of the Creative Commons Attribution License (CC BY). The use, distribution or reproduction in other forums is permitted, provided the original author(s) and the copyright owner(s) are credited and that the original publication in this journal is cited, in accordance with accepted academic practice. No use, distribution or reproduction is permitted which does not comply with these terms. 